\title{
Influence of resveratrol release on the tissue response to mechanically adaptive cortical implants
}

Jessica K. Nguyen, ${ }^{1,2}$ Mehdi Jorfi, ${ }^{3 \#}$ Kelly L. Buchanan, ${ }^{1,2}$ Daniel J. Park, ${ }^{1}$ E. Johan Foster,, 3 Dustin J. Tyler, ${ }^{1,2}$ Stuart J. Rowan, ${ }^{5}$ Christoph Weder, ${ }^{3}$ and Jeffrey R. Capadona ${ }^{1,2, *}$

${ }^{1}$ Department of Biomedical Engineering, Case Western Reserve University, 2071 Martin Luther King Jr. Drive, Wickenden Bldg, Cleveland, OH 44106, USA

${ }^{2}$ Advanced Platform Technology Center, Louis Stokes Cleveland Department of Veterans Affairs Medical Center, 10701 East Blvd, 151 W/APT, Cleveland, OH 44106-1702, USA

${ }^{3}$ Adolphe Merkle Institute, University of Fribourg, Chemin des Verdiers 4, 1700 Fribourg, Switzerland

${ }^{4}$ Virginia Tech, Department of Materials Science \& Engineering \& Macromolecules and Interfaces Institute, 445 Old Turner Street, 213 Holden Hall, Blacksburg VA 24061, USA

${ }^{5}$ Department of Macromolecular Science and Engineering, Case Western Reserve University, 2100 Adelbert Road, Kent Hale Smith Bldg, Cleveland, OH 44106-7202, USA

\#Present address: Department of Chemical Engineering, Massachusetts Institute of Technology, Cambridge, MA 02139, USA

*Denotes corresponding author

Direct correspondence to:

Jeffrey R. Capadona, Ph.D.

Case Western Reserve University

10900 Euclid Avenue

Cleveland, $\mathrm{OH}$

Email: jeffrey.capadona@case.edu

Office: (216) 368-5486 


\begin{abstract}
The stability and longevity of recordings obtained from intracortical microelectrodes continues to remain an area of concern for neural interfacing applications. The limited longevity of microelectrode performance has been associated with the integrity of the blood brain barrier (BBB) and the neuroinflammatory response to the microelectrode. Here, we report the investigation of an additive approach that targets both mechanical and chemical factors believed to contribute to chronic BBB instability and the neuroinflammatory response associated with implanted intracortical microelectrodes. The implants investigated were based on a mechanically adaptive, compliant nanocomposite (NC), which reduces the tissue response and tissue strain. This material was doped with various concentrations of the antioxidant resveratrol with the objective of local and rapid delivery. In vitro analysis of resveratrol release, antioxidant activity, and cytotoxicity suggested that a resveratrol content of $0.01 \%$ was optimal for in vivo assessment. Thus, probes made from the neat NC reference and probes containing resveratrol (NC Res) were implanted into the cortical tissue of rats for up to sixteen weeks. Histochemical analysis suggested that at three days post-implantation, neither materials nor therapeutic approaches (independently or in combination) could alter the initial wound healing response. However, at two weeks post-implantation, the NC Res implant showed a reduction in activated microglia/macrophages and improvement in neuron density at the tissue-implant interface when compared to the neat NC reference. However, sixteen weeks post-implantation, when the antioxidant was exhausted, NC Res and the neat NC reference exhibited similar tissue responses. The data show that NC Res provides short-term, short-lived benefits due to the antioxidant release, and a long-term reduction in neuroinflammation on account of is mechanical adaptive, compliant nature. Together, these results demonstrate that local delivery of resveratrol can provide an additive advantage by providing a consistent reduction in the tissue response.
\end{abstract}

Keywords: Resveratrol, Mechanically adaptive nanocomposite, Intracortical microelectrodes, Neuroinflammation 


\section{Introduction}

Chronic recordings from intracortical microelectrodes provide a platform to enable neural control for motor restoration.[1] A variety of reports have described successful motor control tasks in patients with tetraplegia, including control of a computer cursor, control of a prosthetic limb (reach and grasp), point-and-click communication, and speech synthesis.[2-5] Although top performing arrays have been implanted for over 4 years, a majority of studies still display daily signal instability and decreases in viable recording channels over time. $[6,7]$

While there are several noted failure modes for intracortical microelectrodes, it is widely regarded that the proximity of neurons and characteristics of the tissue surrounding microelectrodes play a crucial role in the stability and integration of implanted microelectrodes.[8-10] Recent work by the Bellamkonda group has demonstrated that maintaining the integrity of the blood-brain barrier influences recording stability.[11] Several mechanisms are believed to contribute to prolonged BBB dysfunction surrounding implanted microelectrodes.

First, traditional intracortical electrode materials are much stiffer than the brain tissue. In silico studies suggest that the mechanical mismatch induces substantial strain on the surrounding tissue, exacerbating the inflammatory response and neurodegeneration. $[9,10,12$, 13] These studies further suggest that reduction of micromotion-induced strain by using more compliant microelectrode materials can reduce the tissue response. With the development of physiologically responsive mechanically adaptive nanocomposites (NCs), we introduced a new class of intracortical implant materials that are initially rigid to permit insertion without the need of an assistive device insertion aide, but soften after implantation to better match the mechanical characteristics of the surrounding tissue.[14-20] Comprised of cellulose 
nanocrystals (CNC) and polyvinyl acetate (PVAc), these NC materials soften from an initial state (dry at room temperature) upon in vivo implantation. $[16,17]$ In the case of the composite comprising $12 \% \mathrm{v} / \mathrm{v}$ CNCs isolated from tunicates, this mechanical switching is characterized by a change of the tensile storage modulus $E^{\prime}$ from $5 \mathrm{GPa}$ to $12 \mathrm{MPa} \cdot[14,15]$ Chronic implantation of such a compliant $\mathrm{NC}$ has recently been shown to lead to a significant improvement in neuronal density surrounding microelectrodes.[16, 21, 22]

Second, continual BBB leakiness may exacerbate the inflammatory response and accumulation of cytotoxic molecules. Delivery of anti-inflammatory therapies can mediate the tissue response to implanted microelectrodes. Dexamethasone, an anti-inflammatory glucocorticoid, has been administrated via systemic injection [23, 24] and released from hydrogel coatings around neural implants.[25, 26] Most studies reported reduction in reactive astrocytes but little effect on activated microglia/macrophages. Rennaker et al. found that systemic administration of the antibiotic minocycline for up to 4 weeks post-implantation improved the signal to noise ratio (SNR) and the percentage of channels recording units, attributed to reduced reactive cells and increased neuronal survival.[27] However, minocycline provided no benefit towards stabilizing neural recordings at early time points and chronic antibiotic administration is not a sustainable solution. Additionally, several groups have investigated local delivery of a variety of bioactive modulators to enhance neural integration. [24, 28, 29] The Cui group immobilized L1, a neural adhesion molecule, to promote neurite outgrowth and neuronal survival surrounding implanted microelectrodes.[30] The results indicated no loss of neuronal cell bodies and a significant increase in axonal density at the interface.[28, 31] Studies have also considered coating electrodes with neural progenitor 
cells to re-establish neuronal populations, but the feasibility of delivering live cells is still being determined.[29, 32]

We previously reported on successful neuroinflammatory modulation with antioxidant therapy.[33, 34] Inflammatory-mediated oxidative stress events, resulting from dangerously high levels of reactive oxygen species (ROS), can induce corrosion of the electrode site and compromise neuronal health.[34-36] Further, an increase in ROS triggers activation of the NF$\kappa \mathrm{B}$ and AP-1 pathways, key inflammatory pathways that lead to production of inflammatory cytokines.[37] Therefore, antioxidative therapies have the capability to reduce reactive oxygen species accumulation and consequently inflammatory events. However, the neuroinflammatory response is multi-faceted and complex, and thus far, single solutions have not been sufficient to fully mediate the damaging elements.

The combination of compliant electrode materials, which can reduce long-term inflammatory events[21], and local antioxidant delivery may enable a cooperative solution to reduce $\mathrm{BBB}$-mediated damage throughout the implant lifetime, resulting in more stable recordings, throughout the entire implantation time. Curcumin-releasing polyvinyl alcohol (PVA) implants provided a first example of antioxidant-releasing compliant materials in which the acute inflammatory response was shown to be reduced.[33] However, the long-term data suggest that PVA is a less suitable materials platform than the previously employed PVAc/CNC-PVAc NC, causing a loss of effectiveness at chronic time points. By contrast, the PVAc/CNC PVAc NC had been implanted for up to sixteen weeks with demonstrated longterm material stability and biocompatibility.[21] An alternative antioxidant, resveratrol, has demonstrated more potent antioxidant effects than curcumin, improving neuronal populations surrounding intracortical implants for up to four weeks with a single injection.[34] Thus, in 
this study, we propose a system to release resveratrol from PVAc/CNCPVAc NC implants to further stabilize neuron populations around compliant implants.

\section{Methods}

\subsection{Chemicals and reagents}

Pharmaceutical grade, 99\% pure trans-resveratrol powder (Res) was purchased from Mega Resveratrol (Danbury, CT). Poly(vinyl acetate) (PVAc, $\left.M_{w}=100,000\right)$, 2,2-diphenyl-1picrylhydrazyl (DPPH), Triton-X 100, and all other reagents were purchased from Sigma Aldrich. Cellulose nanocrystals (CNCs) used in this study were isolated from tunicates (Styela clava) collected from floating docks in Point View Marina (Narragansett, RI), and prepared by sulfuric acid hydrolysis of the cellulose pulp, according to established protocols, as previously reported.[19, 38] To simulate the ionic composition of endogenous brain fluid, artificial cerebrospinal fluid (ACSF) was prepared following an established protocol[20] by dissolving the following compounds in one liter of deionized water: sodium chloride $(\mathrm{NaCl})=7.25 \mathrm{~g}$, potassium chloride $(\mathrm{KCl})=0.22 \mathrm{~g}$, sodium bicarbonate $\left(\mathrm{NaHCO}_{3}\right)=2.18 \mathrm{~g}$, calcium chloride dihydrate $\left(\mathrm{CaCl}_{2} \cdot 2 \mathrm{H}_{2} \mathrm{O}\right)=0.29 \mathrm{~g}$, monopotassium phosphate $\left(\mathrm{KH}_{2} \mathrm{PO}_{4}\right)=0.17 \mathrm{~g}$, magnesium sulfate heptahydrate $\left(\mathrm{MgSO}_{4} \cdot 7 \mathrm{H}_{2} \mathrm{O}\right)=0.25 \mathrm{~g}$, and $D$-glucose $=1.80 \mathrm{~g}$. Cell culture reagents were purchased from Life Technologies.

\subsection{Preparation of antioxidant-releasing nanocomposite films}

A PVAc stock solution was prepared by dissolving PVAc in dimethylformamide (DMF) at a concentration of $50 \mathrm{mg} / \mathrm{mL}$ by stirring for 3 hours at room temperature (RT). Similarly, stock solutions containing resveratrol were made by separately dissolving the 
antioxidant in DMF (10 mg/mL) by stirring for 1 hour at RT. Lyophilized CNCs were dispersed in $\mathrm{DMF}$ at a concentration of $5 \mathrm{mg} / \mathrm{mL}$ by sonicating for 10 hours at room temperature using a Bandelin Sonorex Technik RL 70 UH sonicator operating at $40 \mathrm{kHz}$. PVAC/CNC PVAc NC nanocempesite films containing $0 \%, 0.005 \%, 0.01 \%, 1.0 \%$ or $3.0 \% \mathrm{w} / \mathrm{w}$ of resveratrol and $15 \% \mathrm{w} / \mathrm{w} \mathrm{CNCs}$ (NC Res) were made by combining appropriate amounts of the above stock solutions and CNC dispersion, and stirring the mixture for 30 minutes at RT. For this paper, resveratrol-containing films will be referred to as $\mathrm{NC}$ Res $(\mathrm{X} \%)$, where $\mathrm{X}$ indicates the percentage of resveratrol. The mixtures were then cast into a Teflon ${ }^{\circledR}$ Petri dish, dried at $70{ }^{\circ} \mathrm{C}$ for 5 days and further dried at $120^{\circ} \mathrm{C}$ under high vacuum in an oven for an additional 24 hours to evaporate all of the solvent. After drying, the NC films were compression-moulded between spacers in a Carver ${ }^{\circledR}$ laboratory press (1000 psi for 2 minutes, followed by an increase of pressure to 3000 psi for 10 minutes) at $90{ }^{\circ} \mathrm{C}$, to yield $\sim 100 \mu \mathrm{m}$ thin films. The NC Res films produced were stored in a desiccator at ambient temperature. NC implants for in vivo experiments were fabricated by laser-micromachining with a $355 \mathrm{~nm}$ wavelength picosecond laser (Model A-355-pico, Oxford Lasers) to a thickness of $\sim 70-110 \mu \mathrm{m}$, a length of $2 \mathrm{~mm}$, and a shank width of $50 \mu \mathrm{m}$. All materials were ethylene oxide sterilized before both in vitro and in vivo experiments.

\subsection{Mechanical characterization}

The mechanical properties of the NC films were characterized by dynamic mechanical analysis (DMA, TA Instruments, Model Q800). Tests were conducted in tensile mode, sweeping the temperature between $23-80{ }^{\circ} \mathrm{C}$ at a fixed frequency of $1 \mathrm{~Hz}$, applying a strain amplitude of $15 \mu \mathrm{m}$ and a heating rate of $5{ }^{\circ} \mathrm{C} / \mathrm{min}$. Samples for mechanical testing were 
prepared by cutting strips $(\sim 30 \mathrm{~mm} \times \sim 6 \mathrm{~mm} \times \sim 100 \mu \mathrm{m})$ from the films. To determine the mechanical properties of the films in the wet state, samples were first swelled in ACSF at 37 ${ }^{\circ} \mathrm{C}$ for one week. After the degree of swelling had been measured, DMA experiments were conducted in tensile mode using a submersion clamp, which allowed mechanical measurements while the NC films were immersed in ACSF. In this case, the temperature sweeps were limited to the range of $25-50{ }^{\circ} \mathrm{C}$ and experiments were conducted with a heating rate of $1{ }^{\circ} \mathrm{C} / \mathrm{min}$, a constant frequency of $1 \mathrm{~Hz}$, and a strain amplitude of $15 \mu \mathrm{m}$. These experiments were repeated five times, and the result was expressed as mean \pm standard deviation.

\subsection{Finite Elemental Modelling (FEM) of antioxidant release}

To estimate antioxidant release from doped NC films, a 2D finite-element model was developed to predict the drug release profile at the implant-tissue interface. The model consisted of a cross-section of a drug-containing NC implant within a tissue block. Boundary conditions were defined as no flux at the tissue borders and open boundary at the implant-tissue interface. Drug delivery through the tissue was modelled as Fickian diffusion. The effect of NC swelling on drug diffusion was not taken into account. Since diffusion properties of resveratrol through brain tissue have not been specifically determined, diffusion parameters were assumed to be similar to dexamethasone because the molecular weight, solubility, and density of dexamethasone closely matches that of resveratrol.[39] The system was defined as a no convection system with isotropic diffusion and first-order elimination kinetics $\left(\mathrm{C}=\mathrm{C}_{0} * \mathrm{e}^{\wedge}(-\right.$ $\mathrm{kt}), \mathrm{k}_{\mathrm{e}}=0.4 \mathrm{hr}^{-1}$ ) (assuming non-enzymatic reactions). The diffusion coefficient through brain tissue was defined as $D_{\text {brain }}=2 \mathrm{e}-6 \mathrm{~cm}^{2} / \mathrm{s}$ and through a porous polymer as $\mathrm{D}_{\text {polymer }}=2.04 \mathrm{e}-10$ $\mathrm{cm}^{2} / \mathrm{s}$. [39] The initial concentration of drug within the implant at $\mathrm{t}=0$ was determined assuming 
a polymer implant of $100 \mu \mathrm{m}$ x $50 \mu \mathrm{m}$ x $2 \mathrm{~mm}$ doped with $0.005 \%, 0.01 \%, 1 \%$ or $3 \% \mathrm{w} / \mathrm{w}$ drug. Percent drug release at the tissue-implant interface with respect to time was determined.

Initial amounts of antioxidant within in vivo implants $(50 \mu \mathrm{m} \times 100 \mu \mathrm{m} \times 2 \mathrm{~mm})$ were estimated as \% weight of the film using Equation 1 and 2.

$$
\begin{aligned}
W_{\text {antiox }}= & \left(W_{\text {film }}\right) x(\% \text { antioxidant }) \\
& \frac{W_{\text {antiox }}}{V_{\text {sample }}}=\frac{W_{\text {implant }}}{V_{\text {implant }}}
\end{aligned}
$$

where $\mathrm{W}_{\text {antiox }}$ is the weight of antioxidant in a film sample, $\mathrm{W}_{\text {film }}$ is the total weight of a film sample, $\%$ antioxidant is the mass $\%$ of antioxidant used to create the sample films, $\mathrm{V}_{\text {sample }}$ is the volume of the film sample, $\mathrm{W}_{\text {implant }}$ is the unknown weight of antioxidant in an in vivo implant, and $\mathrm{V}_{\text {implant }}$ is the volume of an in vivo implant.

\subsection{In vitro antioxidant release}

To determine the release rate of resveratrol from the NC Res films, samples $(\sim 30 \mathrm{~mm}$ $\times \sim 6 \mathrm{~mm} \times \sim 100 \mu \mathrm{m})$ were incubated at $37{ }^{\circ} \mathrm{C}$ in a mixture of $20 \mathrm{~mL}$ of $99.5 \% \mathrm{v} / \mathrm{v}$ ACSF and $0.5 \% \mathrm{v} / \mathrm{v}$ Tween-80, which was added to increase the solubility of the resveratrol in the ACSF. At set time intervals ( $\mathrm{t}=1,2,4,6,8,10,24,29,34,48,55$, and 72 hours), $1 \mathrm{~mL}$ aliquots of the solutions were withdrawn, diluted with $1.5 \mathrm{~mL}$ of neat solvent $(99.5 \% \mathrm{v} / \mathrm{v}$ ACSF and $0.5 \% \mathrm{v} / \mathrm{v}$ Tween-80), and the amount of resveratrol released was detected spectrophotometrically (UVvis 2401-PC spectrophotometer, Shimadzu). The concentration of resveratrol released was calculated using a calibration curve established by measuring the absorbance at $308 \mathrm{~nm}$ of a solution series of resveratrol $(5-30 \mu \mathrm{g} / \mathrm{mL})$ in ACSF/Tween 80 . The amount of resveratrol released (relative to the amount of resveratrol originally present in the NCs) was calculated using Equation 3, where [Res] $]_{U V}$ is the concentration of resveratrol measured by UV-vis 
spectroscopy $(\mathrm{mg} / \mathrm{mL}), \mathrm{V}_{\text {Sample }}$ is the volume of the sample in $\mathrm{mL}, \mathrm{W}_{\text {Film }}$ is the weight of the film in $\mathrm{mg}$, and [Res] Film is the nominal concentration of resveratrol in the film $(\mathrm{mg} / \mathrm{mg})$. This experiment was repeated four times, and the result was expressed as mean \pm standard deviation.

$$
\text { Resveratrol Release }(\%)=\frac{[\text { Res }]_{U V} \times \mathrm{V}_{\text {Sample }}}{\mathrm{W}_{\text {Film }} \times[\mathrm{Res}]_{\text {Film }}} \times 100
$$

\subsection{Cell culture}

BV-2 microglia cells were graciously donated by Dr. Stephen Selkirk and NSC-34 neural stem cells were graciously donated by Dr. Horst von Recum. Both cell types were maintained in DMEM Dulbecco's Modified Eagle Medium (ATCC) supplemented with 10\% fetal bovine serum (Invitrogen) and 1\% penicillin-streptomycin (ATCC). For all experiments, BV-2 and NSC-34 cells were used between passages 5 to 25. To differentiate NSC-34 cells into neuron-like cells, the NSC-34 cells were incubated in differentiation media (DMEM/F12 supplemented with $1 \%$ fetal bovine serum, $0.5 \%$ penicillin-streptomycin, non-essential Amino Acids (NEAA), and $1 \mu \mathrm{M}$ retinoic acid) for 4 days, changing the differentiation media every 2 days. For all in vitro tests, BV-2 cells were seeded at a density of 8000 cells/cm², and NSC-34 cells were seeded at a density of 5000 cells $/ \mathrm{cm}^{2}$. All representative images from the assays detailed below were acquired by fluorescence microscopy using an inverted AxioObserver Z1 (Zeiss) equipped with an AxioCam MRm camera. For each assay, exposure times were held constant between conditions. All samples were tested three times per assay, and a minimum of three assays were performed to ensure consistency and repeatability of the measurements.

\subsubsection{Glial cell viability}


To analyze the effects of the doped NC films on microglia cell viability, a slightly modified version of the LIVE/DEAD ${ }^{\circledR}$ Viability/Cytotoxicity Kit (Life Technologies) was used. BV-2 cells were tested with NC films containing $0.005 \%, 0.01 \%, 1 \%$ or $3 \% \mathrm{w} / \mathrm{w}$ of resveratrol. BV-2 cells were seeded in a 12-well plate and film samples $(1 \mathrm{~cm} \times 1 \mathrm{~cm} \times 70-110$ $\mu \mathrm{m})$ were suspended in the media using an insert and adhesive (Kwik-Sil). Positive (all live) and negative (all dead) controls were performed using the insert and adhesive only, no film. The negative control was established by incubating cells with 70\% methanol for 10 minutes. After 48 hours, the media was removed and the cells were incubated in $8 \mu \mathrm{M}$ ethidium homodimer-1 (EthD-1) and $0.1 \mathrm{mM}$ calcein-AM in complete phosphate buffered saline (PBS) for 30 minutes. The samples were then washed once with PBS. Fluorescent images were taken (488 nm green/live, $594 \mathrm{~nm}$ red/dead) to qualitatively determine the cell viability and cytotoxicity of the different resveratrol concentrations.

\subsection{2. $B V-2$ and NSC-34 co-culture: DHE and LIVE/DEAD ${ }^{\circledR}$}

BV-2 cells and NSC-34 cells were co-cultured to analyze their response to exposure to NC films. Here, we tested only the NC Res (0.01\%), since the NC Res (1\%) and NC Res (3\%) showed cytotoxicity with BV2 microglia. The neat PVAC/CNC PVAc NC was used as a control. In all experiments, NSC-34 cells were first differentiated on 12-well plates for 4 days. Subsequently, BV-2 cells were seeded on tissue-culture treated $0.4 \mu \mathrm{m}$ pore polycarbonate membrane inserts (Sigma-Aldrich). The NSC-34 and BV-2 cells were incubated with the experimental film $(1 \mathrm{~cm} \times 1 \mathrm{~cm} \times 70-110 \mu \mathrm{m})$ suspended in the media for 48 hours. After that time, the BV-2 cells were tested for intracellular superoxide accumulation and NSC-34 cells were analysed for cell viability. 
Dihydroethidium (DHE) labeling was utilized to measure intracellular superoxide anion accumulation in BV-2 cells.[40] Prior to performing the staining, bright-field images were taken of the cells to ensure cell viability. Cells were washed one time with PBS, and then incubated with $3 \mu \mathrm{M}$ DHE in PBS for 30 minutes at room temperature. After one wash in PBS, fluorescent images were taken at $555 \mathrm{nM}$ to qualitatively visualize the DHE within the cells. To quantify DHE staining, total fluorescent intensity of DHE was determined for each image and normalized to total fluorescent intensity of cells only control. Although total cell count varied for the different conditions, data were not normalized to total cell count because antioxidants can affect microglial proliferation.[41] To determine viability of neurons with NC

films, cell morphology was assessed. Differentiated neurons were sensitive to repeated washing steps, therefore Live/Dead staining was not done.

\subsection{Measurement of antioxidant activity of films}

The antioxidant activity of NC Res films was determined by measuring the reduction of 2,2-diphenyl-1-picrylhydrazyl (DPPH), a stable free radical. Samples $(3 \mathrm{~cm} \times 0.5 \mathrm{~mm} \times 70$ $110 \mu \mathrm{m})$ were incubated at $37^{\circ} \mathrm{C}$ in $1 \mathrm{~mL}$ of complete PBS with $0.5 \%$ v/v Tween-80. Neat NC controls, NC Res $(0.005 \%)$ and NC Res $(0.01 \%)$ were tested. To indicate the targeted therapeutic range, resveratrol solutions of $5 \mu \mathrm{M}$ and $25 \mu \mathrm{M}$ were also tested. Previous analysis of resveratrol administration suggested that 5 to $25 \mu \mathrm{M}$ was an effective dosage to modulate inflammation in neural tissue.[34, 42] At set time intervals $(\mathrm{t}=1,3,24,48,72$ hours), the incubation solution was removed and replaced with fresh complete PBS with $0.5 \%$ v/v Tween80. The removed incubation solution was mixed 1:1 with DPPH (100 $\mu \mathrm{M}$ diluted in $95 \%$ ethanol) in a 96 well plate. The plate was incubated at RT in the dark for 30 minutes, and then 
the absorbance of the solution was measured spectrophotometrically at $516 \mathrm{~nm}$. The radical scavenging activity of the resveratrol-containing films was expressed using $X=\frac{A-B}{A}$

$$
\begin{gathered}
\text { \% DPPH Scavenging activity }=\frac{X}{C} * 100 \quad \text { (4 and Equato } \\
\qquad X=\frac{A-B}{A} \quad \text { (4) } \\
\text { \% DPPH Scavenging activity }=\frac{X}{C} * 100
\end{gathered}
$$

(4 and Equation 5,

where $\mathrm{X}$ was the normalized absorbance value of resveratrol loaded NC to neat NC, A was the absorbance values at time ' $\mathrm{t}$ ' of the DPPH solution with neat $\mathrm{NC}$ and $\mathrm{B}$ was the absorbance values at time ' $t$ ' of the DPPH solution with resveratrol loaded NC. In Equation 5, values were normalized to $\mathrm{C}$, the average absorbance of DPPH with $25 \mu \mathrm{M}$ resveratrol, the upper limit of the targeted therapeutic range. All samples were tested three times per trial, and three trials were performed to ensure consistency and repeatability of the measurements.

\subsection{Animal surgery}

Surgical procedures for non-functional microelectrode implantation closely followed established protocols, with minor changes [43-45]. Briefly, forty-eight male Sprague Dawley rats (250 - 300 grams) (Charles River, Spencerville, OH) received implants and were euthanized after three days, two weeks, or sixteen weeks. Prior to surgery, animals were anesthetized with ketamine $(80 \mathrm{mg} / \mathrm{kg})$ and xylazine $(10 \mathrm{mg} / \mathrm{kg})$ administered intraperitoneally (IP). Once anesthetized, the surgical area was shaved, and the animal was mounted on a stereotaxic frame and maintained on isofluorane (0.5-2\%). A single injection of local anesthetic, Marcaine (0.5\%), was administered below the incision site subcutaneously (SQ), then the surgical area was scrubbed with betadine and $70 \%$ isopropanol for sterilization. 
Animal body temperature was maintained on a circulating water pad and vitals were monitored using a blood-oxygen and heart rate measurement system (PulseSense, Nonin Medical, Inc.).

First, a one-inch incision was made at midline to expose the skull, using a scalpel. The surrounding tissue was retracted and a $3 \mathrm{~mm}$ hole was created in the skull, manually, using a biopsy punch (P/N \#536, PSS Select), approximately $3 \mathrm{~mm}$ lateral to midline and $4 \mathrm{~mm}$ caudal to bregma. Then the dura was reflected using a 45 degree dura pick. Animals received either a NC only or NC Res $(0.01 \%)$ implant ( $n=6-8$ for each time point), randomizing which hemisphere was implanted. All implants were inserted approximately $2 \mathrm{~mm}$ deep into the cortical tissue by hand, by the same skilled surgeon. Implants were implanted perpendicular to the surface of the brain, to minimize the footprint of tissue damage, while avoiding larger vasculature. Following implantation, implants were tethered to the skull using Kwik-sil (World Precision Instruments) and UV-cured dental acrylic (Fusio-liquid dentin, Pentron Clinical) over the surgical area and skull. The incision was then closed with 5-0 monofilament polypropylene suture (Henry Schein) and a triple antibiotic ointment was applied to the incision. Once the animal woke from anesthesia, meloxicam $(5 \mathrm{mg} / \mathrm{kg}, \mathrm{SQ}$, once a day for 2 days) and cefazolin (16 mg/kg, SQ, twice a day for 2 days) were administered for potential pain and to prevent infection. Surgical procedures and animal care practices were performed in accordance with the Case Western Reserve University Institutional Animal Care and Use Committees (IACUC).

\subsection{Tissue processing}

At three days, two weeks, or sixteen weeks post-implantation, animals were anesthetized using an intraperitoneal injection of ketamine $(80 \mathrm{mg} / \mathrm{kg})$ and xylazine (10 $\mathrm{mg} / \mathrm{kg}$ ). Each animal was perfused transcardially with 1X PBS (Invitrogen) until the exudate 
was clear. The brain was carefully removed, placed in fresh $10 \%$ sucrose and stored at $4{ }^{\circ} \mathrm{C}$ for up to one week. Prior to sectioning, the tissue was cryoprotected in a step-wise gradient of 10\%-20\%-30\% sucrose (Sigma) in $1 \mathrm{X}$ PBS at $4^{\circ} \mathrm{C}$, until equilibrium was reached at each step. After equilibration in $30 \%$ sucrose, the tissue was frozen at $-80^{\circ} \mathrm{C}$ in optimal cutting temperature compound (Tissue-Tek), sliced axially in $20 \mu \mathrm{m}$ sections at $-25^{\circ} \mathrm{C}$, and mounted on Superfrost ${ }^{\mathrm{TM}}$ Plus microscope slides (Fisher Scientific) to be stored at $-80^{\circ} \mathrm{C}$ until immunohistochemical labelling.

\subsection{Immunohistochemistry}

In preparation for immunostaining, the tissue was removed from $-80{ }^{\circ} \mathrm{C}$ and placed at room temperature in a humidity chamber to prevent dehydration of the tissue. The tissue was fixed with $4 \%$ paraformaldehyde for 15 minutes and then washed three times with 1X PBS, followed by conditioning in 1X PBS with $0.1 \%$ Triton-X 100 (Sigma) (1X PBS-T) for 15 minutes. Tissue was then blocked with goat serum blocking buffer ( $4 \% \mathrm{v} / \mathrm{v}$ serum (Invitrogen), $0.3 \% \mathrm{v} / \mathrm{v}$ Triton-X 100, $0.1 \% \mathrm{w} / \mathrm{v}$ sodium azide (Sigma)) to prevent nonspecific binding. The tissue was incubated in primary antibody diluted in goat serum blocking buffer at $4{ }^{\circ} \mathrm{C}$ overnight. The following primary antibodies were used: mouse anti-glial fibrillary acidic protein (GFAP) (1:500, Invitrogen) to stain astrocytes, rabbit anti-immunoglobulin $\mathrm{G}(\operatorname{IgG})$ (1:100, AbDSerotec) to quantify blood brain barrier stability, mouse anti-CD68 (ED1) (1:100, Chemicon) to mark activated microglia/macrophages, and mouse anti-neuronal nuclei (NeuN) (1:250, Millipore) to mark neurons. On the following day, the tissue was washed six times for 5 minutes each with $1 \mathrm{X}$ PBS-T, then incubated for two hours at room temperature with Alexa Fluor conjugated secondary antibodies (1:1000 in goat serum blocking buffer) and 
counterstained with 4',6-diamidino-2-phenylindole (DAPI) to stain total cell nuclei. The tissue was again washed six times with $1 \mathrm{X}$ PBS-T for 5 minutes each. To remove tissue autofluorescence, the tissue was placed in $0.5 \mathrm{mM}$ copper sulfate buffer $(50 \mathrm{mM}$ Ammonium Acetate, pH 5.0) (Sigma) for 10 minutes.[44] Finally, the tissue was rinsed with distilled water and mounted with Fluoromount-G (Southern Biotech) on microscope slides for imaging.

\subsection{Quantitative analysis}

Following immunohistochemistry, slides were imaged using a 10X objective on AxioObserver Z1 (Zeiss) equipped with an AxioCamMRm (Zeiss). MosaiX software (Zeiss) was used to capture and stitch 16 separate images to provide a larger field of view without compromising resolution. Exposure times were held constant for each cellular marker. The acquired images were then linearized and exported as 16-bit tagged image file (TIF) with minimal compression to optimize intensity analysis. Representative images have been slightly enhanced only for presentation purposes to accurately reflect our experimental data.

For all images except NeuN, a custom MATLAB program (MINUTE) was used to analyze the fluorescent intensity profiles as a function of distance from the implant site. For each image, the implant hole was manually defined. The program quantified the intensity of cellular marker expression for each $2 \mu \mathrm{m}$ bin up to $1500 \mu \mathrm{m}$ away from the edge of the implant hole. The quantified fluorescent intensities were then normalized to background which was defined as the average intensity 1000 to $1050 \mu \mathrm{m}$ away from the interface. The fluorescent intensity profiles as a function of distance from the implant site were acquired for each image. For each stain, six slices per animal were analysed and averaged by animal. The area under the curve (AUC) for each profile was calculated using MATLAB and averaged for each stain, time 
point, and implant type at 0 to 50,50 to 100,100 to 150 , and 150 to $200 \mu \mathrm{m}$ from the implanttissue interface.

To quantify the neuronal population around the site of implantation, the implant hole was manually defined in Adobe Photoshop. Concentric rings up to $200 \mu \mathrm{m}$ from the implant were created and the number of neurons within each ring was manually counted. The neuronal density was calculated and converted to percent to sham background by normalizing to neuronal density from age-matched sham animals for each time point.

\subsection{Statistical analysis}

For all in vitro experiments, a minimum of three trials $(\mathrm{N}=3, \mathrm{n}=9)$ were used for statistical evaluation $(\mathrm{N} \geq 3)$. Here, $\mathrm{N}=$ the number of trials, while $\mathrm{n}=$ the total number of samples. Statistical analysis was determined with Minitab 16. For the Live/Dead assays a oneway analysis of variance (ANOVA) with a Tukey's post-hoc test was used to find significance. For all other assays, a Student's t-test was utilized to determine significance. To compare the fluorescent intensity profiles between different implant types in vivo, the AUCs for each stain were averaged per animal $(\mathrm{N}=6-8)$ and analysed by using a general linear ANOVA model. For NeuN, the number of neurons per area was used for statistical analysis. In all cases, statistical significance was defined as $\mathrm{p}<0.05$.

\section{Results}

\subsection{Material characterization}

Dry NC implants containing $15 \%$ w/w CNCs (but no resveratrol) were previously shown to be readily inserted through the pia mater into the cerebral cortex of a rat without the need for instive insertion aides, and to soften considerably once implanted in the brain 
tissue.[16, 17] In order to confirm that the introduction of resveratrol did not alter this mechanically adaptive behaviour, the mechanical properties of NC Res films were investigated using dynamic mechanical analysis (DMA). Table 1 summarizes the tensile storage moduli $\left(E^{\prime}\right)$ of the NC Res as well as the neat NC control film in the dry and ACSF-swollen state as a function of temperature. All of the materials studied undergo a pronounced modulus reduction from $\sim 6000 \mathrm{MPa}$ to $\sim 10 \mathrm{MPa}$ upon exposure to (emulated) physiological conditions, due to matrix plasticization and/or decoupling of the CNCs on account of competitive hydrogen bonding with water consistent with previous studies in our labs.[14-16] For example, NC Res (3\%) exhibit a reduction of $E^{\prime}$ from $6340 \mathrm{MPa}$ (dry, RT) to $14 \mathrm{MPa}\left(\mathrm{ACSF}-\right.$ swollen, $37{ }^{\circ} \mathrm{C}$ )

(Table 1, Figure S1). Further, Table 1 shows that in the compositional range studied, the amount addition of resveratrol had no significant little-to-no influence impact on the mechanical properties in the dry state. While the data suggest minor differences in $E$ ' in the water-swollen state, these are barely significant and no trend regarding the influence of the Res content can be discerned. Additional Characterization of NC Res indicated that sample undergo aqueous swelling to ca $80 \%$ w/w (Figure S2). Further, thermogravimetric properties (Figure S3) from addition of resveratrol at all concentrations can be seen in Figure S3.

\subsection{Antioxidant release profile}

\section{INSERT TABLE 1}

Systemic administration of resveratrol demonstrated improvement in neuronal populations for up to four weeks after the initial dose in rats.[34] Subsequent biodistribution analysis revealed anti-inflammatory efficacy of 5-25 $\mu \mathrm{M}$ resveratrol delivered to the brain.[42, 46] Therefore, the therapeutic target range in the surrounding tissue was $\sim 25 \mu \mathrm{M}$. Here, the optimal drug concentration for the resveratrol within loaded films was determined using the 
results from finite element analysis, in vitro resveratrol release characterization, and cell culture.

Finite element analysis indicated that drug was released up to $5 \mu \mathrm{m}$ away from the implant surface (Figure 1). Additionally, the analysis showed that $42 \%$ of the antioxidant was released after 2.7 hours and $100 \%$ was released after ca. 24 hours. Calculated values of resveratrol contained within in vivo implants are indicated in Table 2. Assuming a diffusion volume of $5 \mu \mathrm{m}$ from the implant surface and the starting concentration of the films, the NC Res $(0.005 \%)$ film fell within the target range. However, given that the FEM model did not account for metabolic breakdown, chemical reactions, or swelling properties of the NC, it is assumed that the release may be much lower than the model indicates and thus, higher concentration films were created.

\section{INSERT FIGURE 1}

\section{INSERT TABLE 2}

In vitro resveratrol release studies were performed to establish the timeframe in which the resveratrol was released from the NC under (emulated) physiological conditions. The release studies were carried out by submerging NC Res films in ACSF at $37^{\circ} \mathrm{C}$ and monitoring the UV absorbance of resveratrol in the supernatant solution as a function of time. The cumulative release percentage, relative to the total amount of resveratrol nominally included in the composition, is shown in Table S1. After the drug release experiments were carried out, the drug-loaded films were found to be colourless, indicating that the majority of the NC Res films were released into the medium within a timeframe of $\sim 70$ hours. However, only about 
$\sim 64 \pm 4 \% \mathrm{w} / \mathrm{w}$ of the resveratrol comprised in the $\mathrm{NC}$ was detected by UV-vis after 72 hours (See Table S1).

The fact that the percentage of antioxidants released from the NC films was lower than $100 \% \mathrm{w} / \mathrm{w}$ could be due to a number of factors. For example, the decomposition of a fractional amount of the antioxidants during processing conditions can cause undesirable hydrolysis reactions in the active antioxidant compounds. Several factors, such as light, solvents or $\mathrm{pH}$ conditions, have been reported in the literature-as contributing to the degradation of resveratrol.[47, 48] We found (data not shown) that antioxidants studied here decomposed upon exposure of the antioxidant solutions (dissolved in DMF) to oxygen at room temperature. Finally, trapping of a small amount of resveratrol in the NC matrix may also be possible. Based on these considerations, and to allow for a comparison of the release kinetics between compositions, the data presented in Table $\mathbf{S 1}$ were normalized as antioxidant released percentage versus time (Figure 2). Additionally, as expected, the absolute amount released from the films scaled with the drug content; the NC Res (3\%) films released ca. 3.5 times more resveratrol than the NC Res (1\%) films after 72 hours incubation in ACSF at $37{ }^{\circ} \mathrm{C}$. Unfortunately, it was not possible to detect the release of the antioxidants photometrically in low dose nanocomposites (NC Res (0.005\%) and NC Res (0.01\%)) due to the limited sensitivity of the technique. However, the relative percentage of antioxidant released was assumed to hold for the low dose nanocomposites.

\section{INSERT FIGURE 2}

\subsection{In vitro validation}


In order to determine the optimal antioxidant concentration for in vivo implants, it was important to first investigate the potential cytotoxicity and antioxidative activity of the various concentrations. To this end, in vitro cytotoxicity assays were performed to ensure safety of released antioxidant levels. Further, antioxidative activity assays (DPPH and DHE staining), were utilized to assess the efficacy of released antioxidants in the reduction of accumulated ROS.

\subsubsection{Glial cell cytotoxicity}

Cell viability assays were initially performed by exposing BV2 microglia to neat NC samples or NC Res films containing $0.005 \%, 0.01 \%, 1 \%$, or $3 \%$ resveratrol (Figure 3). Exposure to neat NC films had no effect on cell viability when compared to a cells only control. Additionally, exposure to NC Res $+0.005 \%$ and $0.01 \%$ resveratrol demonstrated no substantial cell death. However, NC Res $+1 \%$ and $3 \%$ resveratrol induced considerable cell death compared to the controls. Therefore, NC Res $+1 \%$ or $3 \% \mathrm{w} / \mathrm{w}$ resveratrol films were not used in further experiments due to the exhibited cytotoxicity.

\section{INSERT FIGURE 3}

\subsubsection{Antioxidant activity}

Next, the DPPH assay was utilized to investigate the antioxidative activity of NC Res $(0.005 \%)$ and NC Res $(0.01 \%)$. Reduction of DPPH by resveratrol indicates the ability to reduce ROS species. In Figure 4, the targeted therapeutic range of 5-25 $\mu \mathrm{M}$ is denoted by the grayed region and values were normalized such that reduction by $25 \mu \mathrm{M}$ resveratrol is defined as $100 \%$ DPPH reduction. NC Res $(0.005 \%)$ films do not exhibit antioxidative efficacy within 
the targeted range. For NC Res $(0.01 \%)$, antioxidative activity was maximal after 24 hours $(76 \%)$ and within the therapeutic range for up to 48 hours.

\section{INSERT FIGURE 4}

\subsubsection{Intracellular ROS and neuron cytotoxicity}

NC Res $(0.01 \%)$ films were found to have no cytotoxic effects on glial cells and exhibited antioxidant activity within the target therapeutic range. Further in vitro experiments were performed to confirm neuron viability and ROS reduction with NC Res $(0.01 \%)$ films. Since neurons exhibit a higher cytotoxic sensitivity than microglia cells, NC Res $(0.01 \%)$ films were incubated with neuron cultures for 48 hours (Figure 5A). NC Res showed no effect on neuronal morphology or processes. To determine potential effects on intracellular ROS production, DHE fluorescence was detected on microglia exposed to NC Res $(0.01 \%)$ for 48 hours (Figure 5B). Exposure of microglia to NC surfaces alone did not affect intracellular ROS. Quantification of DHE fluorescence showed that microglia incubated with NC Res $(0.01 \%)$ had significantly less intracellular ROS than neat NC controls. Therefore, implants were fabricated from $0.01 \%$ resveratrol-containing $\mathrm{NC}$ (NC Res) films for in vivo characterization.

\section{INSERT FIGURE 5}

\subsection{In vivo characterization}

Following validation of in vitro cytocompatibility and antioxidative activity, NC Res $(0.01 \%)$ neural implants were analyzed for their ability to reduce the neuroinflammatory response compared to non-loaded NC. Immunostaining of brain slices for various 
neuroinflammatory markers at the implant-tissue interface was performed for several time points that were selected to monitor acute and chronic inflammation. Insertion of intracortical microelectrodes induces tissue and vascular damage, allowing infiltration of blood cells and proteins into the brain tissue. Immunostaining for immunoglobulin $\mathrm{G}(\operatorname{IgG})$ indicated damage and permeability of the blood brain barrier (BBB).[10] Microglia/macrophages play a major role in the brain's immune response to foreign implants, inducing recruitment of inflammatory cell types and releasing cytotoxic factors such as reactive oxygen species (ROS). Up-regulation of activated microglia/macrophages around the implants was indicated by CD68+ immunostaining.[49] The extent of astrocytic encapsulation following implantation was measured with GFAP+ immunostaining.[50] Most importantly, to ensure high quality neural recordings, neurons should be in close proximity of the electrode.[51] In order to quantify the neuronal density around the implant, neuronal nuclei $(\mathrm{NeuN})$ was counted as a function of distance from each type of implant.

\subsubsection{Three day time point}

At three days post-implantation, no statistically significant differences were apparent for any of the inflammatory markers (Figure 6). No substantial glial scarring was visible around either the NC or NC Res implants (Figure 6A-C, M). A small, but diffuse, accumulation of serum protein $\operatorname{IgG}$ was observed up to $800 \mu \mathrm{m}$ away from the interface for both implant types (Figure 6D-F, N). Similarly, the population of activated microglia/macrophages (CD68+) was detected as far as approximately $600 \mu \mathrm{m}$ away from both types of implants (Figure 6G-I, O). Both implant conditions also caused significant neuronal 
dieback (Figure 6J-L, P), reducing neuronal populations to $\sim 40 \%$ near the implants (0 to 50 $\mu \mathrm{m})$, compared to age-matched sham animals.

\section{INSERT FIGURE 6}

\subsubsection{Two week time point}

The most significant differences between implant conditions were seen at two weeks post-implantation (Figure 7). NC Res implants exhibited significantly improved neuronal populations around the implant at 0 to $50 \mu \mathrm{m}$ compared to neat NC (Figure 7J-L, P). In fact, the neuron density around NC Res was statistically similar to that of the age-matched sham at 0 to $50 \mu \mathrm{m}$ away from the implant site. Meanwhile, NC implants had significant neuronal dieback at 0 to $50 \mu \mathrm{m}$ compared to age-matched sham animals. At distances greater than 50 $\mu \mathrm{m}$ from the interface, both implant types exhibited full recovery of neurons compared to agematched sham animals. Additionally, expression of CD68+ microglia/macrophages was significantly reduced around NC Res implants (Figure 7G-I, O). The CD68+ expression extended to $\sim 300-400 \mu \mathrm{m}$ for both implant types. However, NC Res implants exhibited significantly less CD68+ immunostaining at 0 to $50 \mu \mathrm{m}$ away from the implant.

While reduced CD68+ cell populations correspond with improved neuronal populations, astrocytic scaring and BBB instability did not. For both conditions, glial scarring extended up to $600 \mu \mathrm{m}$ from the implant, and both conditions were statistically similar (Figure 7A-C, M). Further, IgG+ immunostaining showed statistically similar profiles between both conditions, with staining extending up to $\sim 500 \mu \mathrm{m}$ from the implant (Figure 7D-F,N).

\section{INSERT FIGURE 7}




\subsubsection{Sixteen week time point}

At sixteen weeks post-implantation, there was no statistically significant difference between NC and NC Res implants for any of the inflammatory markers (Figure 8). For both neat NC and NC Res, the glial scarring was more compacted, extending up to $300-400 \mu \mathrm{m}$ from the implant site (Figure 8A-B, I). IgG+ immunostaining was low at sixteen weeks, and similar to earlier time points, there was no statistically significant difference between the two types of implants (Figure 8C-D, J). There was no statistically significant difference between the expression of CD68 around NC and NC Res implants at sixteen weeks post-implantation (Figure 8E-F, K). Further, no significant difference in neuronal density was observed between NC and NC Res at any distance from the implant (Figure 8G-H, L). Significant reduction in neuron density ( $\sim 50 \%)$ was evident from 0 to $50 \mu \mathrm{m}$ from the interface for NC Res compared to age-matched sham animals. However, at further distances, full recovery to native levels was evident for both implants.

\section{INSERT FIGURE 8}

\section{Discussion}

The characteristics of the tissue surrounding microelectrodes play a crucial role in the stability and integration of implanted devices. Recent literature has supported the hypothesis that the integrity of the blood-brain barrier $(\mathrm{BBB})$ may be a major factor in the neuroinflammatory response to microelectrodes. Specifically, examination of the tissue 
response surrounding implanted microwire and Michigan-style microelectrodes revealed that the BBB integrity immediately surrounding the implantation site was compromised.[52, 53] Additionally, the extent of neuroinflammation has been correlated to the proximity of the implant to large vessels.[54] Most important to device function, several studies have begun to correlate microelectrode performance the stability of the BBB. For example, Kozai et al. demonstrated that increased bleeding intensity was linked to a reduction in SNR.[55] Further, Saxena et al. correlated the long-term stability of functional single unit recordings with changes in BBB permeability.[11] The study by Saxena et al. was the first to directly relate increased BBB leakiness to reduced quality of neural recordings.

Since the integrity of the BBB appears to play a critical role in intracortical microelectrode performance, we have explored several mechanisms to inhibit potential causes for BBB breakdown in parallel. The administration of antioxidants has been shown to improve BBB integrity and neuronal proximity at acute time points.[33, 34] However, long-term delivery methods to minimize potential undesirable consequences are still under investigation.[35, 46] Alternatively, our initial NC implants designed to reduce tissue strain were able to improve neuronal proximity for up to sixteen weeks post-implantation.[21, 22] However, fluctuations in BBB integrity and microglial activation, which may affect neuron recording capabilities throughout device lifetime, were noted during the implantation period. The current study describes a strategy to combine mechanically adaptive NC materials with therapeutic antioxidant delivery as a cooperative system to improve BBB healing and implant integration.

At both three days (Figure 6) and sixteen weeks (Figure 8) post-implantation, NC Res implants had no discernible difference from NC controls. At three days, the insertion damage 
is presumably overwhelming any potential actions/therapeutic effects of the antioxidant. This is consistent with wound healing events in response to insertion damage being the predominant issue immediately following implantation. As such, reduction of insertion-mediated damage is critical and several groups have investigated the effects of insertion speed, tip geometry, and probe size during implantation.[56-58] For example, Kozai et al. explored utilizing ultra-small microelectrodes or avoiding large vasculature with in vivo two-photon microscopy to reduce insertion damage.[59, 60] Alternatively, at sixteen weeks post-implantation, it was expected that the effects of the antioxidant delivery would wear off. It was anticipated that due to complete release of resveratrol, there would be no difference between NC and NC Res implants (as seen in Figure 8). We have previously shown that our NC implants reduce the neuroinflammatory response compared to traditional silicon implants, at the most chronic time points (16 weeks) post-implantation.[21, 22, 33, 61] Therefore, our goal in the design of the combinatory antioxidant and compliant implant approach was to maintain the reduced neuroinflammatory response throughout the duration of implantations, thereby allowing for stable recordings throughout implant lifetime. We set out to maximize the short-term advantages of antioxidant therapy, without the possible long-term dosing complications, while also benefiting from the long-term neuroinflammatory improvements provided by our more compliant NC implants.

Characterization of antioxidant-containing films used in this study indicated no changes in material properties due to incorporation of resveratrol. (Table 1, Figure S1-S3) While in vitro release and antioxidative activity of resveratrol were noted up to 48-72 hours (Figure 2, 4), in vivo results exhibited benefits from NC Res (0.01\% resveratrol-containing NC) for at least two weeks post-implantation (Figure 7) but not at three-days post implantation. Delayed 
reaction to resveratrol delivery may be due to the mechanism by which resveratrol affects inflammation. Resveratrol can directly neutralize and scavenge free radicals. However, it can also inhibit mRNA production of pro-inflammatory cytokines and inhibit NF-kB and NOS expression.[62] Reduction in pro-inflammatory molecules and expression of inflammatory genes may induce changes in inflammatory cell phenotype and lead to a delayed change in environmental neurotoxicity.

Here, NC Res implants reduced activation of microglia compared to neat NC implants at the two week time point. Significant reduction in microglial activation can influence the inflammatory environment and allow for increased neuronal survival, which is seen in Figure 7K, P. Further, the neuron viability from NC Res implants indicated a similar improvement to a single systemic dose of resveratrol, showing $\sim 75 \%$ neuronal nuclei density at two weeks.[34] However, the systemic resveratrol study indicated reduction in BBB permeability at two weeks with resveratrol dosed animals, which is not seen in the present study (Figure 7N). NC alone has been shown to reduce BBB permeability,[21] so the addition of resveratrol may not provide a further benefit. The mechanism of action for system resveratrol delivery may also differ from local delivery. Systemic resveratrol delivery may pre-emptively and directly affect bloodderived cells and factors involved in inflammation, which have been found to be the predominant cells involved in mediating neurodegeneration.[63]. However, resveratrol still exhibits neuroprotection regardless of type of delivery.

Our lab continues to investigate antioxidative strategies to reduce device-induced neuroinflammation. Experiments are underway to improve resveratrol delivery to the brain and investigate the feasibility of continual injections for a more prolonged effect. Further, it may be feasible to locally deliver resveratrol until the reserves are exhausted, then subsequently 
provide systemic resveratrol administration. Alternatively, our lab has explored the use of surface-conjugated superoxide dismutase (SOD) mimetics to provide sustained ROS scavenging around silicon implants.[42] SOD mimetics could potentially be conjugated and released from the NC for another combined approach to modulate neuroinflammatory events. Together, reducing tissue strain and the oxidative environment surrounding implanted microelectrodes promise to address additive mechanisms which lead to neural tissue damage and corrosion of electrode materials.

\section{Conclusions}

In summary, the results of this study demonstrate that the addition of local antioxidant delivery can further improve neuron density surrounding already beneficial compliant implants. Incorporation of resveratrol into the $\mathrm{NC}$ had no effect on material properties and antioxidant release was expected for up to 72 hours. With the in vivo studies, at three days postimplantation, insertion damage and wound healing events dominated the neuroinflammatory response. However, beneficial effects of local resveratrol delivery were seen at two weeks postimplantation, with significant reduction in microglial activation and improvement in neuron density. NC only and NC Res exhibited similar tissue responses sixteen weeks postimplantation when the antioxidants were exhausted. Therefore, the additionat of Res to NC implants exhibited short-term benefits of antioxidant treatment and the long-term reduction in neuroinflammation by compliant implants. Together, these results demonstrate that local delivery of antioxidants can provide an additive advantage to enhance attenuation of the tissue response to compliant implants. 


\section{Acknowledgements}

This work was supported by the Department of Biomedical Engineering and Case School of Engineering at Case Western Reserve University through lab start-up fund, as well the CWRU Jane and David Watterson Endowment funds of Dr. J. Thomas Mortimer, and the NIH Neural Engineering and Rehabilitation Training Grant (J. Nguyen) (5T32EB004314-14). Additional funding on this research was supported in part by the Department of Veterans Affairs Merit Review (B7122-R, B1495-R), Presidential Early Career Award for Scientist and Engineers (PECASE). The authors also gratefully acknowledge financial support from the Adolphe Merkle Foundation and the Swiss National Science Foundation (NRP 62 No. 406240_126046 and No. P2FRP2_151665). The authors have no conflicts of interest related to this work to disclose. The authors also acknowledge the support of K. Potter-Baker for her help determining initial design parameters, A. Hess-Dunning for laser micromachining the in vivo implants, K. Kovach for his assistance with cell culture, and M. Gitomer, and C. Uthe for their help with animal surgeries and tissue processing. 
References:

[1] Wolpaw JR, Birbaumer N, Heetderks WJ, McFarland DJ, Peckham PH, Schalk G, et al. Brain-computer interface technology: a review of the first international meeting. IEEE transactions on rehabilitation engineering 2000;8:164-73.

[2] Hochberg LR, Bacher D, Jarosiewicz B, Masse NY, Simeral JD, Vogel J, et al. Reach and grasp by people with tetraplegia using a neurally controlled robotic arm. Nature 2012;485:372-5.

[3] Simeral JD, Kim S-P, Black MJ, Donoghue JP, Hochberg LR. Neural control of cursor trajectory and click by a human with tetraplegia 1000 days after implant of an intracortical microelectrode array. Journal of Neural Engineering 2011;8:025027.

[4] Guenther FH, Brumberg JS, Wright EJ, Nieto-Castanon A, Tourville JA, Panko M, et al. A wireless brain-machine interface for real-time speech synthesis. PLoS One 2009;4:e8218.

[5] Bacher D, Jarosiewicz B, Masse NY, Stavisky SD, Simeral JD, Newell K, et al. Neural Point-and-Click Communication by a Person With Incomplete Locked-In Syndrome. Neurorehabil Neural Repair 2014;29:462-71.

[6] Barrese JC, Rao N, Paroo K, Triebwasser C, Vargas-Irwin C, Franquemont L, et al. Failure mode analysis of silicon-based intracortical microelectrode arrays in non-human primates. J Neural Eng 2013;10:066014.

[7] Jorfi M, Skousen JL, Weder C, Capadona JR. Progress towards biocompatible intracortical microelectrodes for neural interfacing applications. Journal of Neural Engineering 2015;12:011001.

[8] Polikov VS, Tresco PA, Reichert WM. Response of brain tissue to chronically implanted neural electrodes. J Neurosci Methods 2005;148:1-18.

[9] Biran R, Martin DC, Tresco PA. Neuronal cell loss accompanies the brain tissue response to chronically implanted silicon microelectrode arrays. Experimental Neurology 2005;195:115-26.

[10] McConnell GC, Rees HD, Levey AI, Gutekunst C-A, Gross RE, Bellamkonda RV. Implanted neural electrodes cause chronic, local inflammation that is correlated with local neurodegeneration. J Neural Eng 2009;6:056003.

[11] Saxena T, Karumbaiah L, Gaupp EA, Patkar R, Patil K, Betancur M, et al. The impact of chronic blood-brain barrier breach on intracortical electrode function. Biomaterials 2013;34:4703-13.

[12] Subbaroyan J, Martin DC, Kipke DR. A finite-element model of the mechanical effects of implantable microelectrodes in the cerebral cortex. Journal of Neural Engineering 2005;2:103-13.

[13] Lee H, Bellamkonda RV, Sun W, Levenston ME. Biomechanical analysis of silicon microelectrode-induced strain in the brain. Journal of Neural Engineering 2005;2:81-9.

[14] Capadona JR, Shanmuganathan K, Tyler DJ, Rowan SJ, Weder C. Stimuli-responsive polymer nanocomposites inspired by the sea cucumber dermis. Science 2008;319:1370.

[15] Shanmuganathan K, Capadona JR, Rowan SJ, Weder C. Biomimetic mechanically adaptive nanocomposites. Prog Polym Sci 2010;35:212-22.

[16] Harris JP, Hess AE, Rowan SJ, Weder C, Zorman CA, Tyler DJ, et al. In vivo deployment of mechanically adaptive nanocomposites for intracortical microelectrodes. Journal of Neural Engineering 2011;8:046010.

[17] Hess AE, Potter K, Tyler DJ, Zorman CA, Capadona JR. Environmentally-controlled Microtensile Testing Of Mechanically-adaptive Polymer Nanocomposites For ex vivo Characterization. J Vis Exp 2013;78:e50078.

[18] Dagnon KL, Shanmuganathan K, Weder C, Rowan S. Water-Triggered Modulus Changes of Cellulose Nanofiber Nanocomposites with Hydrophobic Polymer Matrices. Macromolecules 2012;45:4707-15. 
[19] Jorfi M, Roberts MN, Foster EJ, Weder C. Physiologically Responsive, Mechanically Adaptive Bio-Nanocomposites for Biomedical Applications. ACS Appl Mater Interfaces 2013;5:1517-26.

[20] Annamalai PK, Dagnon KL, Monemian S, Foster EJ, Rowan SJ, Weder C. WaterResponsive Mechanically Adaptive Nanocomposites based on Styrene-Butadiene Rubber and Cellulose Nanocrystals - Processing Matters. ACS Appl Mat Interf 2014;6:967-76.

[21] Nguyen JK, Park DJ, Skousen JL, Hess-Dunning A, Tyler DJ, Rowan SJ, et al. Mechanically-compliant intracortical implants reduce the neuroinflammatory response. Journal of Neural Engineering 2014;11:056014.

[22] Harris JP, Capadona JR, Miller RH, Healy BC, Shanmuganathan K, Rowan SJ, et al. Mechanically adaptive intracortical implants improve the proximity of neuronal cell bodies. Journal of Neural Engineering 2011;8:066011.

[23] Spataro L, Dilgen J, Retterer S, Spence AJ, Isaacson M, Turner JN, et al. Dexamethasone treatment reduces astroglia responses to inserted neuroprosthetic devices in rat neocortex. Exp Neurol 2005;194:289-300.

[24] Shain W, Spataro L, Dilgen J, Haverstick K, Retterer S, Isaacson M, et al. Controlling cellular reactive responses around neural prosthetic devices using peripheral and local intervention strategies. IEEE Trans Neural Syst Rehabil Eng 2003;11:186-8.

[25] Zhong Y, Bellamkonda RV. Dexamethasone-coated neural probes elicit attenuated inflammatory response and neuronal loss compared to uncoated neural probes. Brain Res 2007;1148:15-27.

[26] Luo X, Matranga C, Tan S, Alba N, Cui XT. Carbon nanotube nanoreservior for controlled release of anti-inflammatory dexamethasone. Biomaterials 2011;32:6316-23.

[27] Rennaker RL, Miller J, Tang H, Wilson DA. Minocycline increases quality and longevity of chronic neural recordings. J Neural Eng 2007;4:L1-5.

[28] Azemi E, Lagenaur CF, Cui XT. The surface immobilization of the neural adhesion molecule L1 on neural probes and its effect on neuronal density and gliosis at the probe/tissue interface. Biomaterials 2011;32:681-92.

[29] Green RA, Lim KS, Henderson WC, Hassarati RT, Martens PJ, Lovell NH, et al. Living electrodes: Tissue engineering the neural interface. Engineering in Medicine and Biology Society (EMBC), 2013 35th Annual International Conference of the IEEE2013. p. 6957-60.

[30] Azemi E, Stauffer WR, Gostock MS, Lagenaur CF, Cui XT. Surface immobilization of neural adhesion molecule L1 for improving the biocompatibility of chronic neural probes: In vitro characterization. Acta Biomater 2008:1208-17.

[31] Kolarcik CL, Bourbeau D, Azemi E, Rost E, Zhang L, Lagenaur CF, et al. In vivo effects of L1 coating on inflammation and neuronal health at the electrode-tissue interface in rat spinal cord and dorsal root ganglion. Acta Biomaterialia 2012;8:3561-75.

[32] Azemi E, Gobbel GT, Cui XT. Seeding neural progenitor cells on silicon-based neural probes. Journal of Neurosurgery 2010;113:673-81.

[33] Potter KA, Jorfi M, Householder KT, Foster EJ, Weder C, Capadona JR. Curcuminreleasing mechanically-adaptive intracortical implants improve the proximal neuronal density and blood-brain barrier stability. Acta Biomater 2014;10:2209-22.

[34] Potter KA, Buck AC, Self WK, Callanan ME, Sunil S, Capadona JR. The effect of resveratrol on neurodegeneration and blood brain barrier stability surrounding intracortical microelectrodes. Biomaterials 2013;34:7001-15.

[35] Potter-Baker KA, Capadona JR. Reducing the "Stress": Antioxidative Therapeutic and Material Approaches May Prevent Intracortical Microelectrode Failure. ACS Macro Letters 2015:275-9.

[36] Prasad A, Xue Q-S, Sankar V, Nishida T, Shaw G, Streit WJ, et al. Comprehensive characterization and failure modes of tungsten microwire arrays in chronic neural implants. J Neural Eng 2012;9:056015. 
[37] Gloire G, Legrand-Poels S, Piette J. NF- $\kappa B$ activation by reactive oxygen species: Fifteen years later. Biochemical Pharmacology 2006;72:1493-505.

[38] Favier V, Chanzy H, Cavaille JY. Polymer Nanocomposites Reinforced by Cellulose Whiskers. Macromolecules 1995;28:6365-7.

[39] Saltzman WM, Radomsky ML. Drugs released from polymers: diffusion and elimination in brain tissue. Chemical Engineering Science 1991;46:2429-44.

[40] Zanetti M, d'Uscio LV, Peterson TE, Katusic ZS, O'Brien T. Analysis of superoxide anion production in tissue. In: Baker JPFaAH, editor. Methods in Molecular Medicine. Totowa, NJ: Humana Press Inc.; 2005. p. 65-72.

[41] Fulda S, Debatin KM. Resveratrol modulation of signal transduction in apoptosis and cell survival: a mini-review. Cancer detection and prevention 2006;30:217-23.

[42] Potter-Baker KA, Nguyen JK, Kovach KM, Gitomer MM, Srail TW, Stewart WG, et al. Development of Superoxide Dismutase Mimetic Surfaces to Reduce Accumulation of Reactive Oxygen Species Surrounding Intracortical Microelectrodes Journal of Materials Chemistry B 2014;2:2248-58.

[43] Potter KA, Buck AC, Self WK, Capadona JR. Stab injury and device implantation within the brain results in inversely multiphasic neuroinflammatory and neurodegenerative responses. J Neural Eng 2012;9:046020.

[44] Potter KA, Simon JS, Velagapudi B, Capadona JR. Reduction of autofluorescence at the microelectrode-cortical tissue interface improves antibody detection. J Neurosci Methods 2012;203:96-105.

[45] Potter-Baker KA, Ravikumar M, Burke AA, Meador WD, Householder KT, Buck $\mathrm{AC}$, et al. A comparison of neuroinflammation to implanted microelectrodes in rat and mouse models. Biomaterials 2014;34:5637-46.

[46] Potter-Baker KA, Stewart WG, Tomaszewski WH, Wong CT, Meador WD, Ziats NP, et al. Implications of chronic daily anti-oxidant administration on the inflammatory response to intracortical microelectrodes. J Neural Eng 2015;12:046002.

[47] Jensen JS, Wertz CF, O'Neill VA. Preformulation stability of trans-resveratrol and trans-resveratrol glucoside (Piceid). J Agric Food Chem 2010;58:1685-90.

[48] Mallapragada SK, Peppas NA. Crystal dissolution-controlled release systems: I. Physical characteristics and modeling analysis. Journal of Controlled Release 1997;45:8794.

[49] Dijkstra C, Dopp E, Joling P, Kraal G. The heterogeneity of mononuclear phagocytes in lymphoid organs: distinct macrophage subpopulations in the rat recognized by monoclonal antibodies ED1, ED2 and ED3. Immunology 1985;54:589-99.

[50] Eddleston M, Mucke L. Molecular profile of reactive astrocytes-implications for their role in neurologic disease. Neuroscience 1993;54:15-36.

[51] Buzsáki G. Large-scale recording of neuronal ensembles. Nat Neurosci 2004;7:44651.

[52] Winslow BD, Christensen MB, Yang WK, Solzbacher F, Tresco PA. A comparison of the tissue response to chronically implanted Parylene-C-coated and uncoated planar silicon microelectrode arrays in rat cortex. Biomaterials 2010;31:9163-72.

[53] Skousen J, Merriam S, Srivannavit O, Perlin G, Wise K, Tresco P. Reducing surface area while maintaining implant penetrating profile lowers the brain foreign body response to chronically implanted planar silicon microelectrode arrays. Prog Brain Res 2011;194C:167-80.

[54] Rousche PJ, Normann RA. Chronic recording capability of the Utah Intracortical Electrode Array in cat sensory cortex. J Neurosci Methods 1998;82:1-15.

[55] Kozai TDY, Jaquins-Gerstl AS, Vazquez AL, Michael AC, Cui XT. Brain Tissue Responses to Neural Implants Impact Signal Sensitivity and Intervention Strategies. ACS Chemical Neuroscience 2015;6:48-67. 
[56] Bjornsson CS, Oh SJ, Al-Kofahi YA, Lim YJ, Smith KL, Turner JN, et al. Effects of insertion conditions on tissue strain and vascular damage during neuroprosthetic device insertion. J Neural Eng 2006;3:196-207.

[57] Rousche PJ, Normann RA. A method for pneumatically inserting an array of penetrating electrodes into cortical tissue. Ann Biomed Eng 1992;20:413-22.

[58] Sharp AA, Ortega AM, Restrepo D, Curran-Everett D, Gall K. In vivo penetration mechanics and mechanical properties of mouse brain tissue at micrometer scales. IEEE Trans Biomed Eng 2009;56:45-53.

[59] Kozai TDY, Langhals NB, Patel PR, Deng X, Zhang H, Smith KL, et al. Ultrasmall implantable composite microelectrodes with bioactive surfaces for chronic neural interfaces. Nature Materials 2012;11:1065-73.

[60] Kozai TDY, Marzullo TC, Hooi F, Langhals NB, Majewska AK, Brown EB, et al. Reduction of neurovascular damage resulting from microelectrode insertion into the cerebral cortex using in vivo two-photon mapping. Journal of Neural Engineering 2010;7:046011.

[61] Sridharan A, Nguyen JK, Capadona JR, Muthuswamy J. Compliant intracortical implants reduce strains and strain rates in brain tissue in vivo. Journal of Neural Engineering 2015;12:036002.

[62] Pangeni R, Sahni JK, Ali J, Sharma S, Baboota S. Resveratrol: review on therapeutic potential and recent advances in drug delivery. Expert Opin Drug Deliv 2014;11:1285-98. [63] Ravikumar M, Sunil S, Black J, Barkauskas D, Haung AY, Miller RH, et al. The Roles of Blood-derived Macrophages and Resident Microglia in the Neuroinflammatory Response to Implanted Intracortical Microelectrodes. Biomaterials 2014;S01429612:8049-64. 
Figure and Table Captions:

Figure 1. FEM estimation of in vivo drug release. A model of a $0.01 \%$ antioxidant-containing $\mathrm{NC}$ implanted within the brain indicates infiltration up to $5 \mu \mathrm{m}$ from the tissue-implant interface and release within the first 24 hours.

Figure 2. Normalized drug release percentage of $\mathrm{NC}$ Res in ACSF at $37{ }^{\circ} \mathrm{C}$. All NCs contain $15 \% \mathrm{w} / \mathrm{w} \mathrm{CNCs}$ and $1 \%$ or $3 \%$ Res, as indicated in the figure. Values represent means \pm standard deviations of $\mathrm{N}=4$ experiments.

Figure 3. Cytotoxicity of NC Res with microglia cells. BV-2 microglia exposed to the neat NC as well as the NC Res $(0.005 \%)$ or NC Res $(0.01 \%)$ remained viable, and look similar to the cells only control. NC Res (1\%) and NC Res (3\%) induce appreciable cytotoxicity. Green indicates live cells and red indicates dead cells. Scale bar $=100 \mu \mathrm{m}$.

Figure 4. Antioxidative activity of $0.005 \%$ and $0.01 \%$ Res containing NC. NC Res films were incubated in PBS with $0.5 \%$ v/v Tween-80 for up to 48 hours. DPPH assay shows that NC Res $(0.01 \%)$ exhibit normalized antioxidative activity within the targeted therapeutic range of 5-25 $\mu \mathrm{M}$ (greyed region).Antioxidative activity was normalized to neat NC controls.

Figure 5. In vitro characterization of NC films containing $0.01 \%$ Res. (A) Neuronal outgrowth and viability are unaffected by $\mathrm{NC}$ or $\mathrm{NC}$ Res $(0.01 \%)$. Scale bar $=100 \mu \mathrm{m}$. (B) Intracellular ROS accumulation indicated by DHE fluorescent dye. (C) Microglia exposed to NC Res $(0.01 \%)$ had significantly less DHE fluorescence than the neat NC. Fluorescent intensity was normalized to cells only controls. ${ }^{*} \mathrm{p}<0.05$ compared to neat $\mathrm{NC}$.

Figure 6. Assessment of the initial inflammatory response at three days post-implantation. No significant difference between types of implants was seen three days after implantation. Both implants induced significant neuronal loss at 0 to $50 \mu \mathrm{m}$ from the interface. $\# \mathrm{p}<0.05$ compared to age-matched sham controls (dotted line). White line denotes implant location. Scale bar $=100$ $\mu \mathrm{m}$.

Figure 7. Assessment of the inflammatory response at two weeks post-implantation. NC Res implants exhibit a significant reduction in CD68+ staining and improvement in neuron density from 0 to $50 \mu \mathrm{m}$ from the interface. ${ }^{*} \mathrm{p}<0.05$ between $\mathrm{NC}$ vs $\mathrm{NC}$ Res. \#p $<0.05$ compared to agematched sham controls (dotted line). White line denotes implant location. Scale bar $=100 \mu \mathrm{m}$. 
Figure 8. Assessment of the inflammatory response at sixteen weeks post-implantation. For all markers tested, no significant difference was seen between NC and NC Res implants. \#p<0.05 compared to age-matched sham controls. White line denotes implant location. Scale bar $=100$ $\mu \mathrm{m}$.

Table 1. Storage moduli $\left(E^{\prime}\right)$ of dry and ACSF-swollen NCs determined by DMA. Data represent averages $(n=5)$ and are shown for the neat $\mathrm{NC}$ as well as for resveratrol (Res) containing NCs loaded with different contents of antioxidant.

Table 2. Estimated amount of antioxidant contained within an in vivo implant. 


\begin{tabular}{|c|c|c|c|c|}
\hline \multirow{2}{*}{ Nanocomposite } & \multirow{2}{*}{$\begin{array}{c}\text { Resveratrol } \\
\text { Content } \\
(\% \mathbf{w} / \mathbf{w})\end{array}$} & \multicolumn{2}{|c|}{ Dry Nanocomposites } & $\begin{array}{c}\text { Swollen } \\
\text { Nanocomposites }\end{array}$ \\
\cline { 3 - 5 } & & $\begin{array}{c}E^{\prime} \text { at } 25^{\circ} \mathrm{C} \\
(\mathrm{MPa})\end{array}$ & $\begin{array}{c}E^{\prime} \text { at } 70{ }^{\circ} \mathrm{C} \\
(\mathrm{MPa})\end{array}$ & $\begin{array}{c}\frac{E^{\prime} \text { at } 37^{\circ} \mathrm{C} \text { after }}{1 \text { week in ACSF }} \\
(\mathrm{MPa})\end{array}$ \\
\hline Neat NC & & $6300 \pm 190$ & $720 \pm 180$ & $13 \pm 1.8$ \\
\hline NC Res & 0.005 & $6100 \pm 350$ & $970 \pm 72$ & $7.0 \pm 3.6$ \\
& 0.01 & $6050 \pm 140$ & $900 \pm 85$ & $6.0 \pm 1.5$ \\
& 1.0 & $6100 \pm 197$ & $851 \pm 67$ & $13 \pm 2.0$ \\
& 3.0 & $6340 \pm 135$ & $840 \pm 205$ & $14 \pm 2.5$ \\
\hline
\end{tabular}

Table 1. 
Table 2

\begin{tabular}{|c|c|c|c|c|}
\hline \multirow{2}{*}{} & \multicolumn{4}{|c|}{ Amount of antioxidant in implant } \\
\cline { 2 - 5 } & $0.005 \%$ film & $0.01 \%$ film & $1 \%$ film & $3 \%$ film \\
\hline Resveratrol & $0.9 \mathrm{ng}$ & $1.8 \mathrm{ng}$ & $182.4 \mathrm{ng}$ & $547.2 \mathrm{ng}$ \\
\hline
\end{tabular}

Table 2 

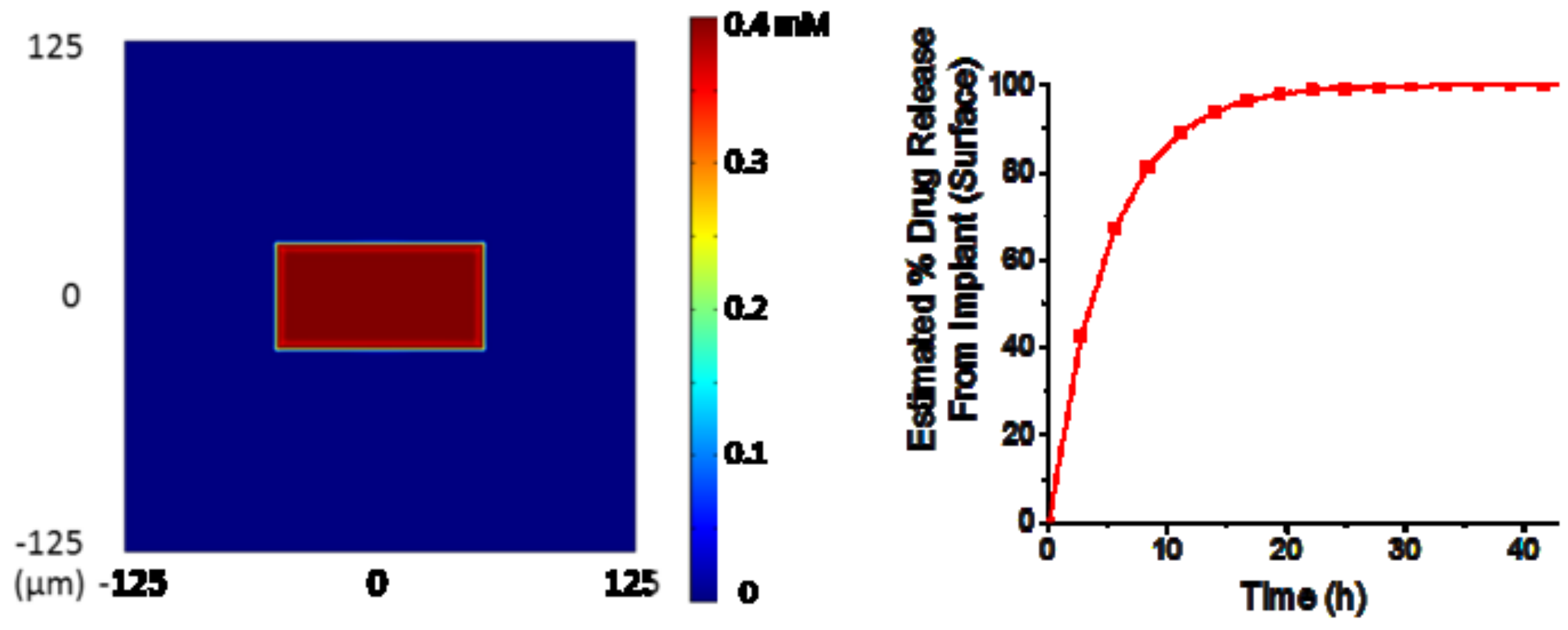


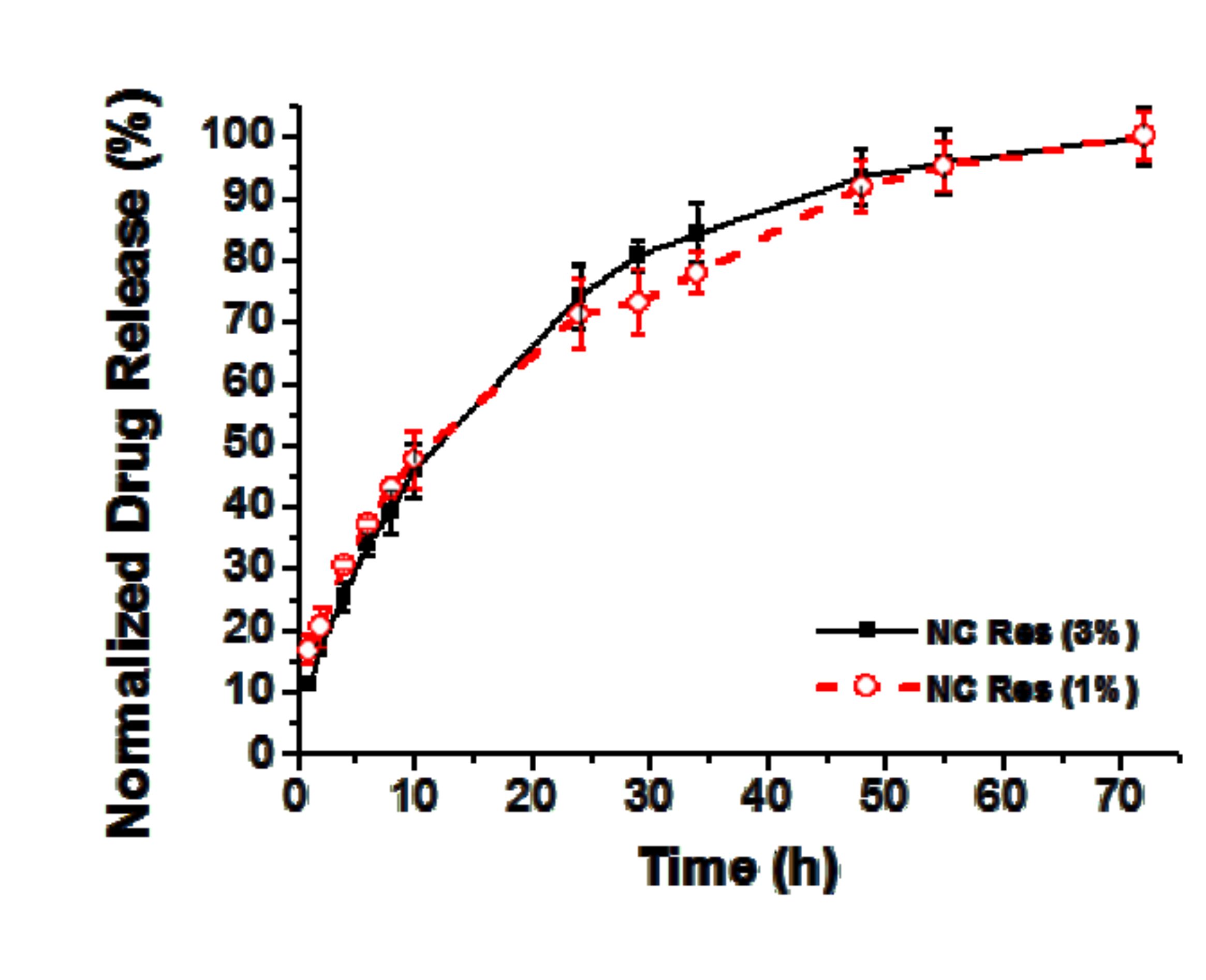

.

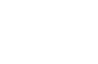


Cells Only

Neat NC

\section{NC Res $(0.005 \%)$}

\section{NC Res $(0.01 \%)$}

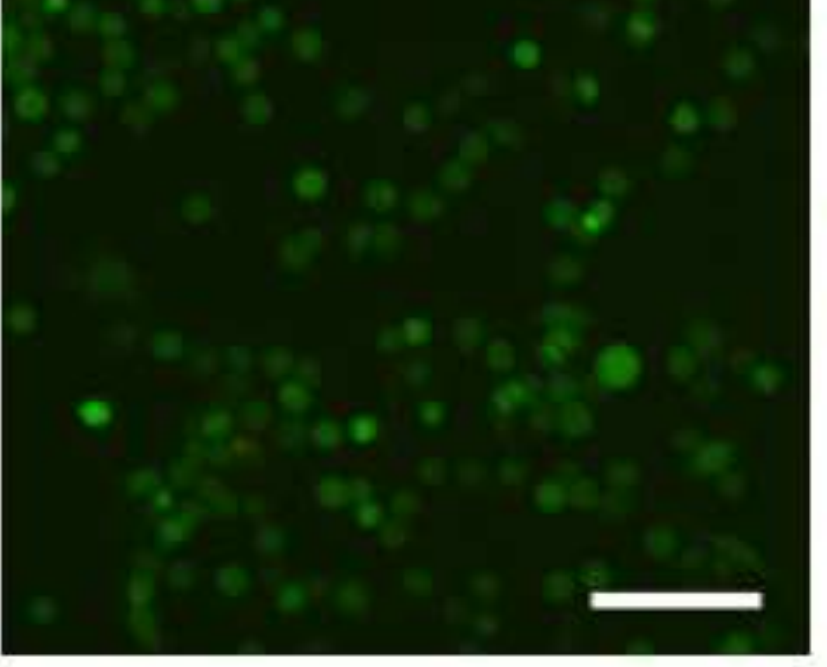

NC Res (1\%)

NC Res (3\%)

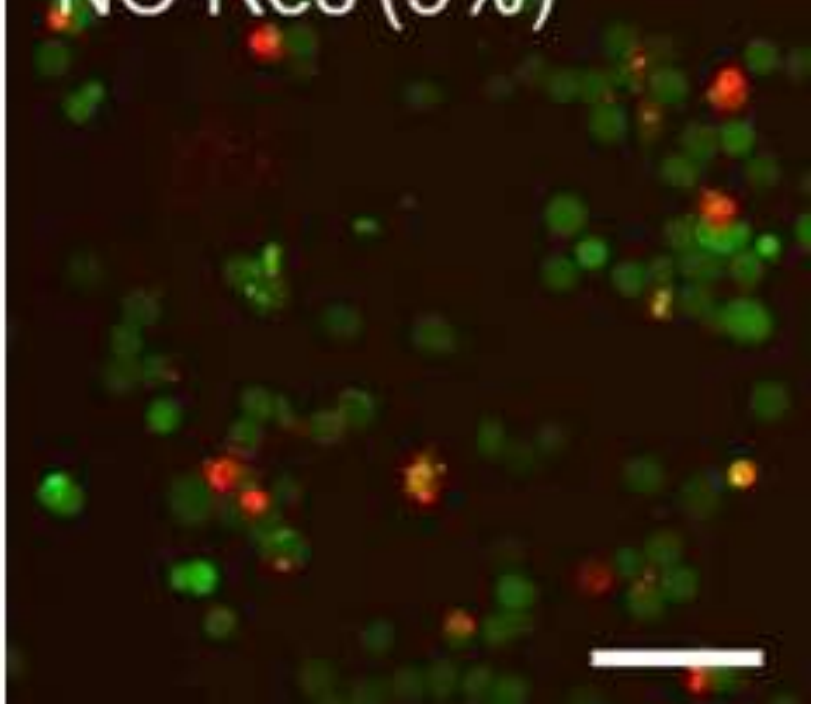




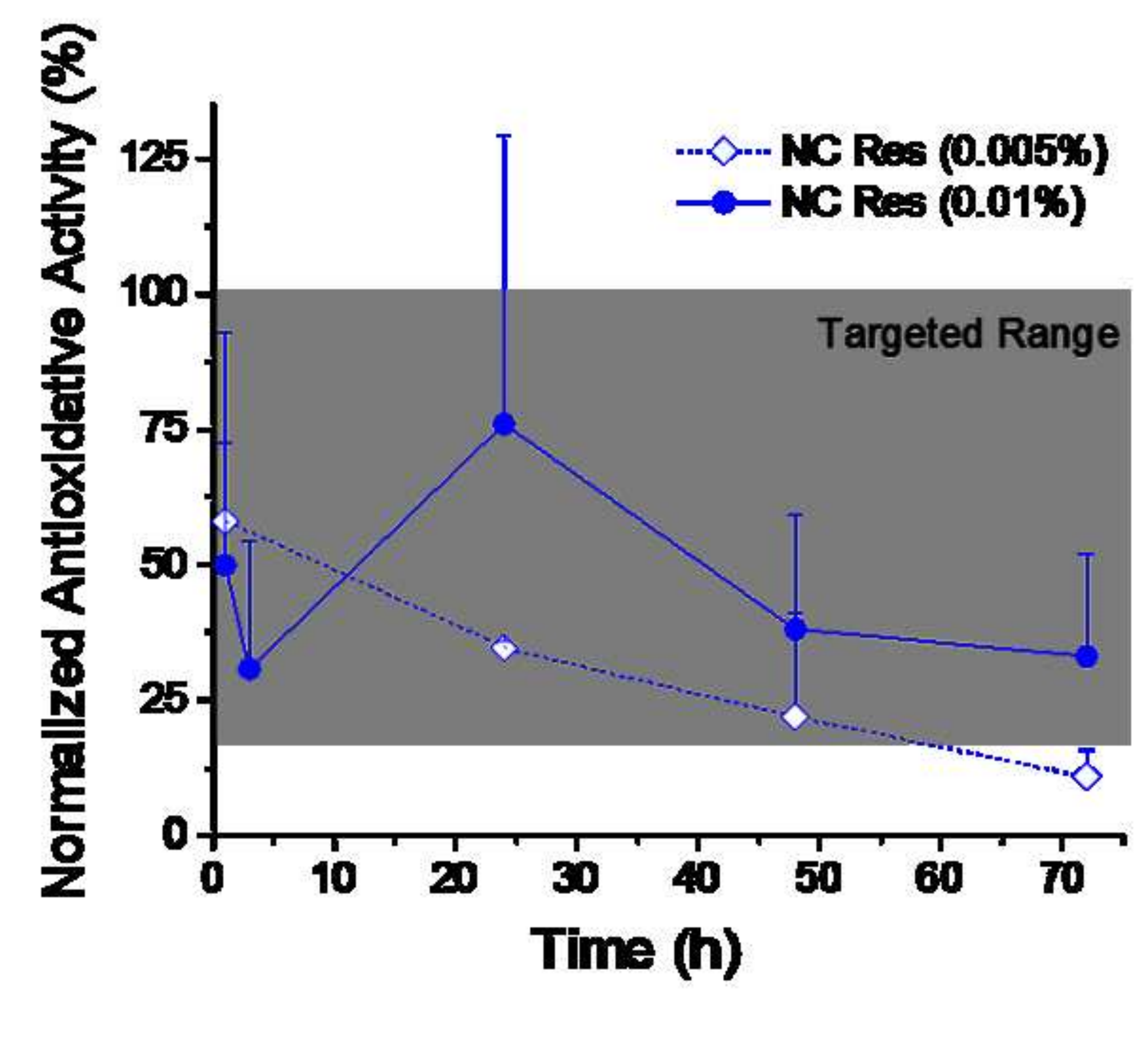

\begin{tabular}{|c|}
\hline 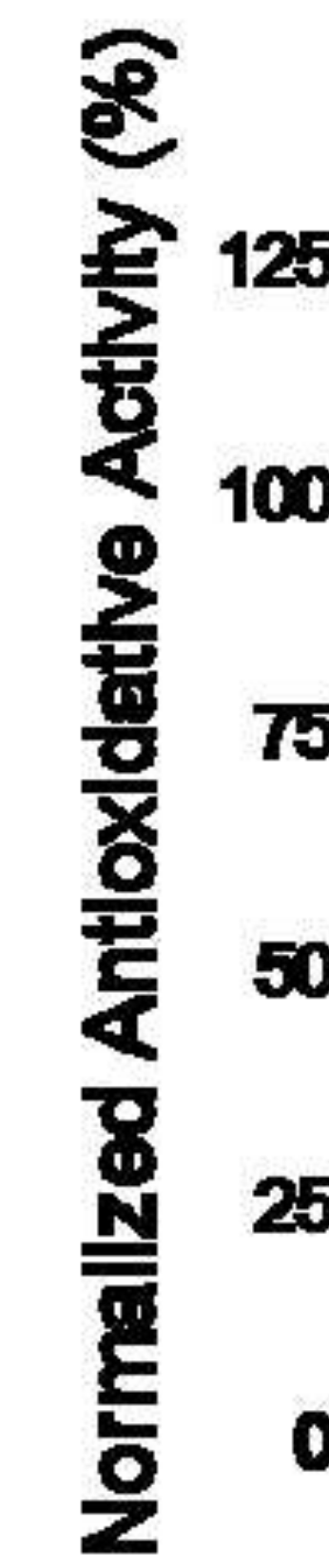 \\
\hline
\end{tabular}
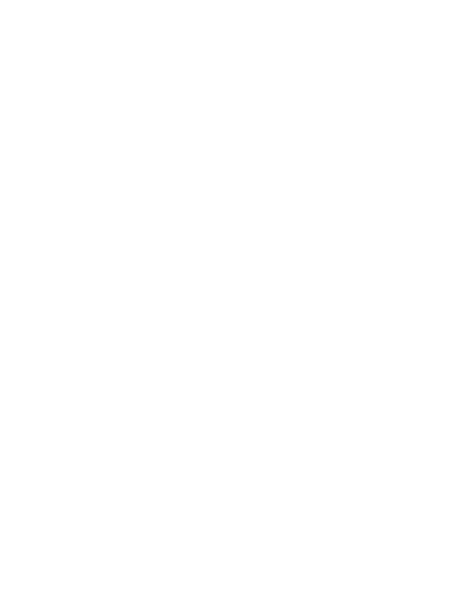
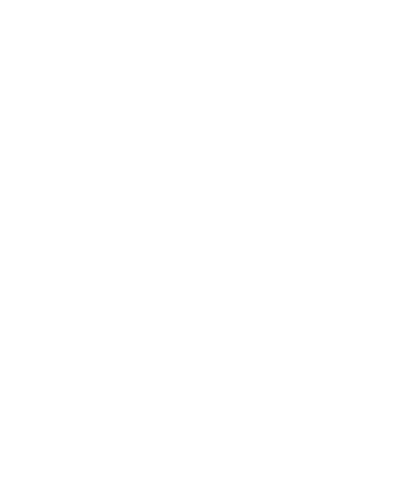

.

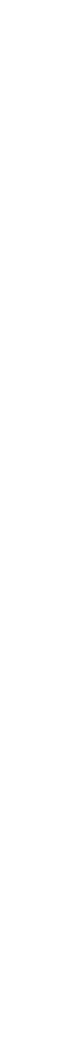

\section{Targeted Range

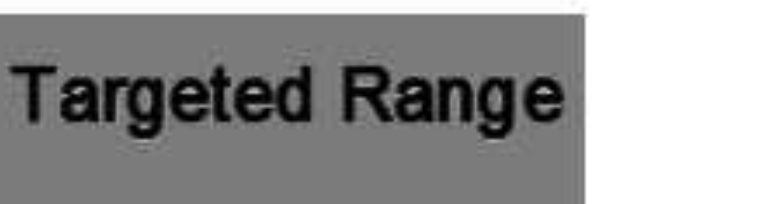

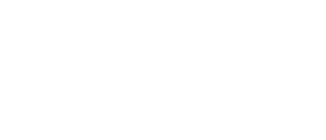

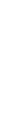

.

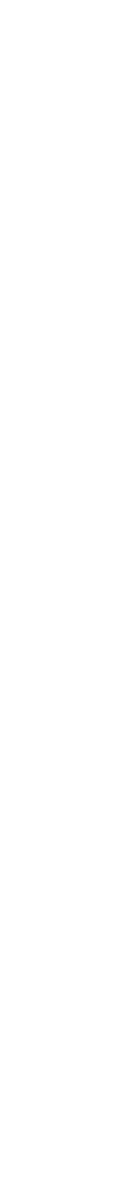

.

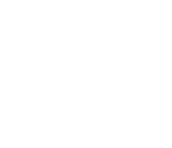
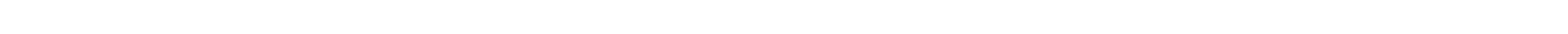
Figure 5

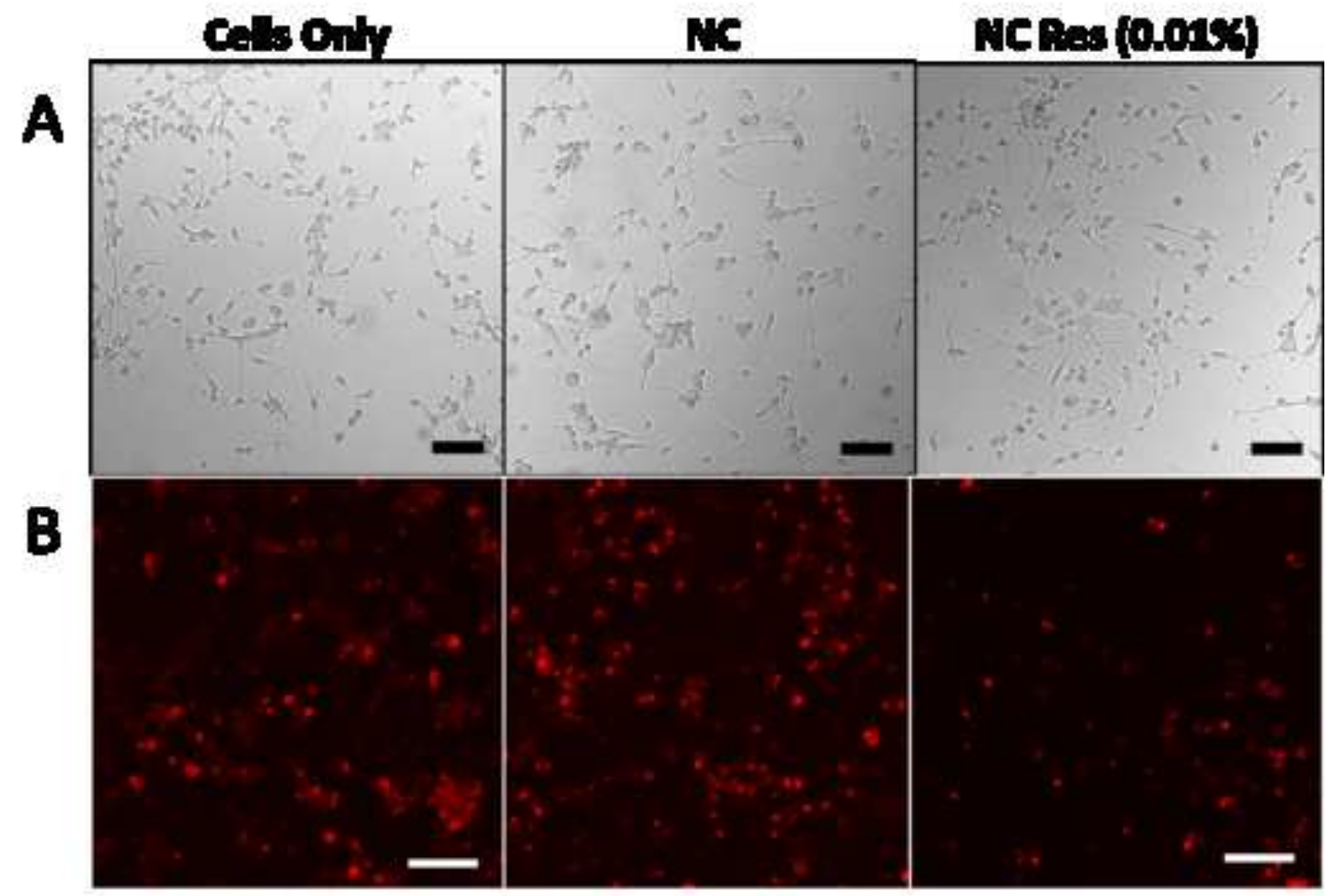

C

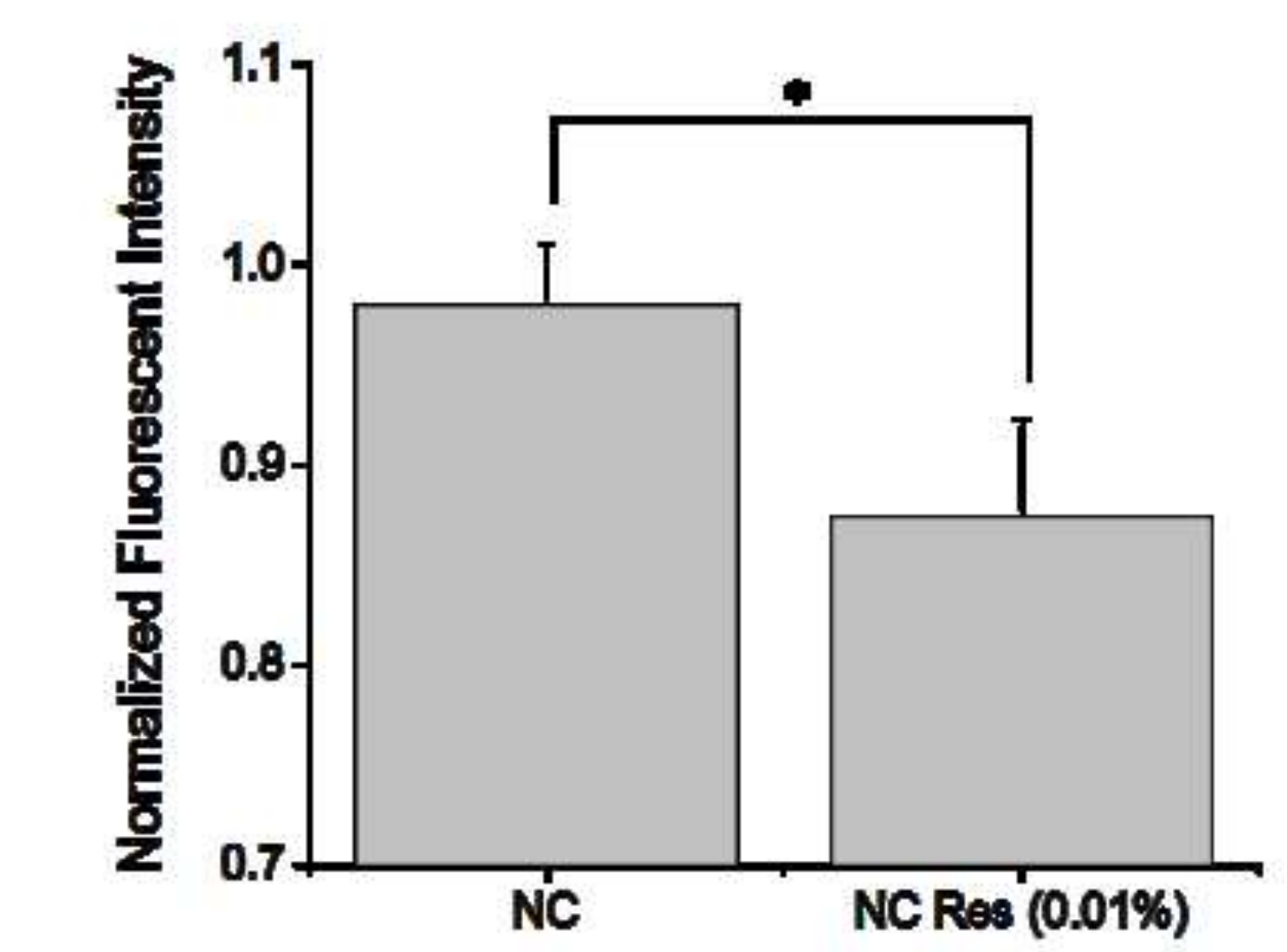

Cels Onh

NC

ACRes (0.0184) 

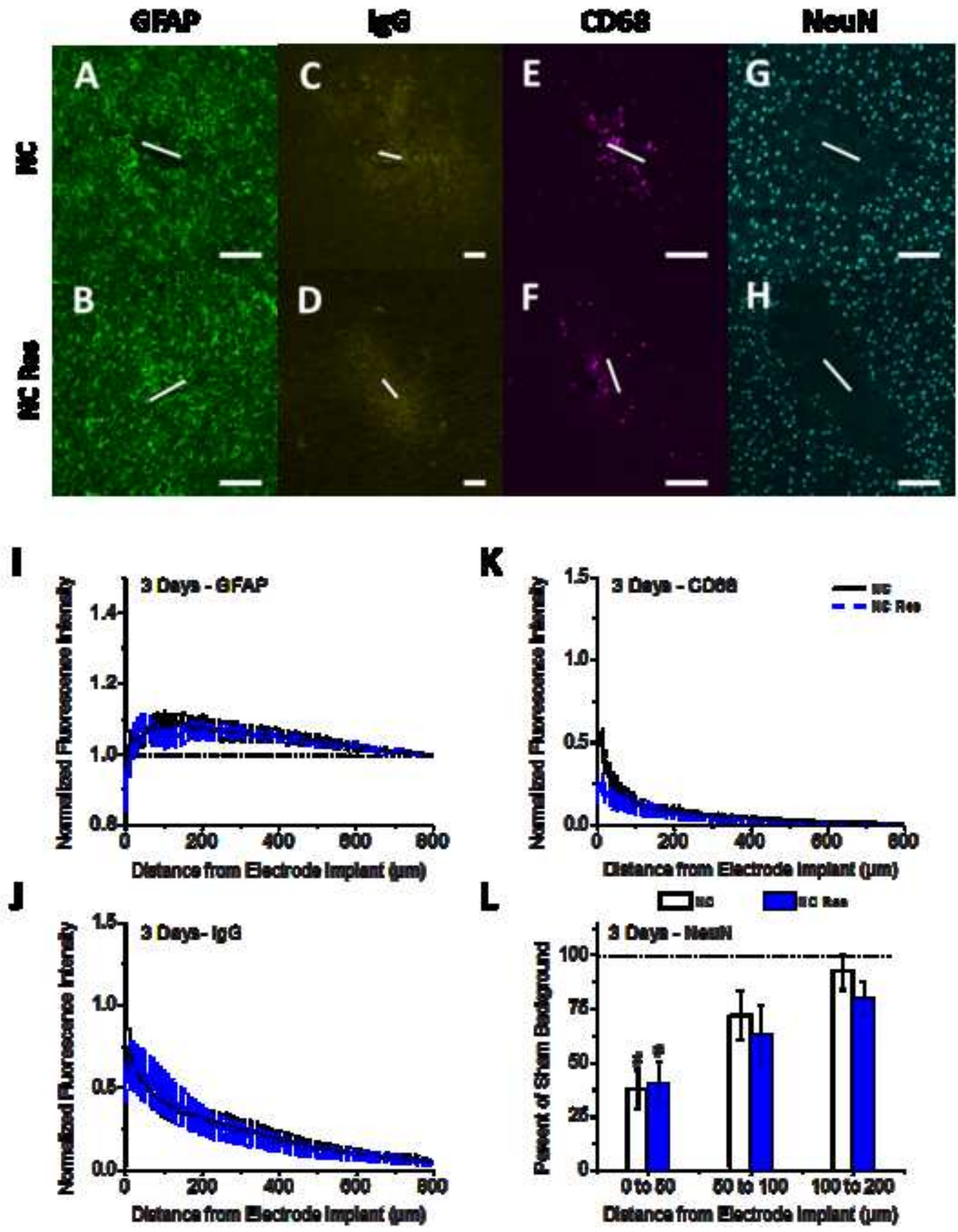


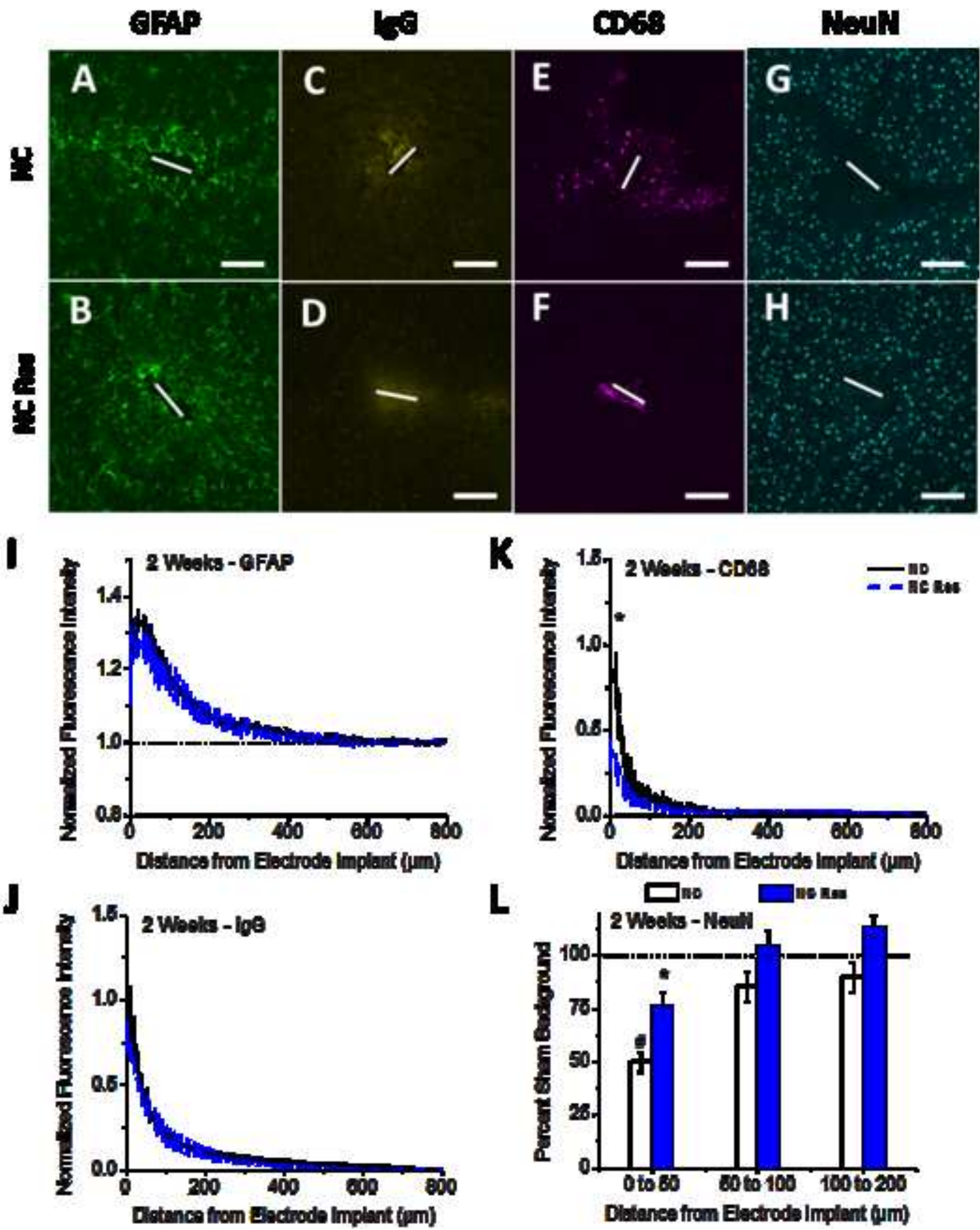




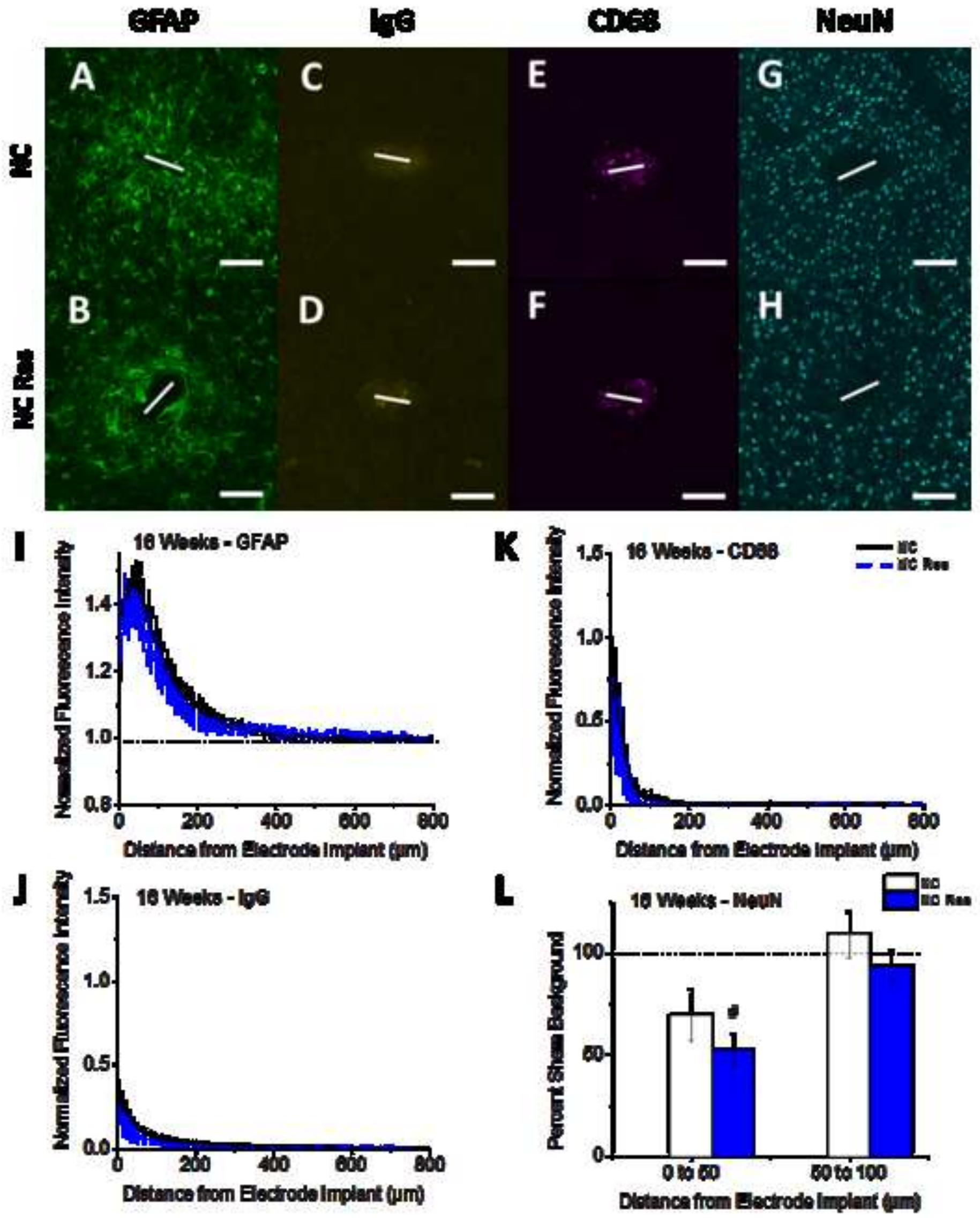



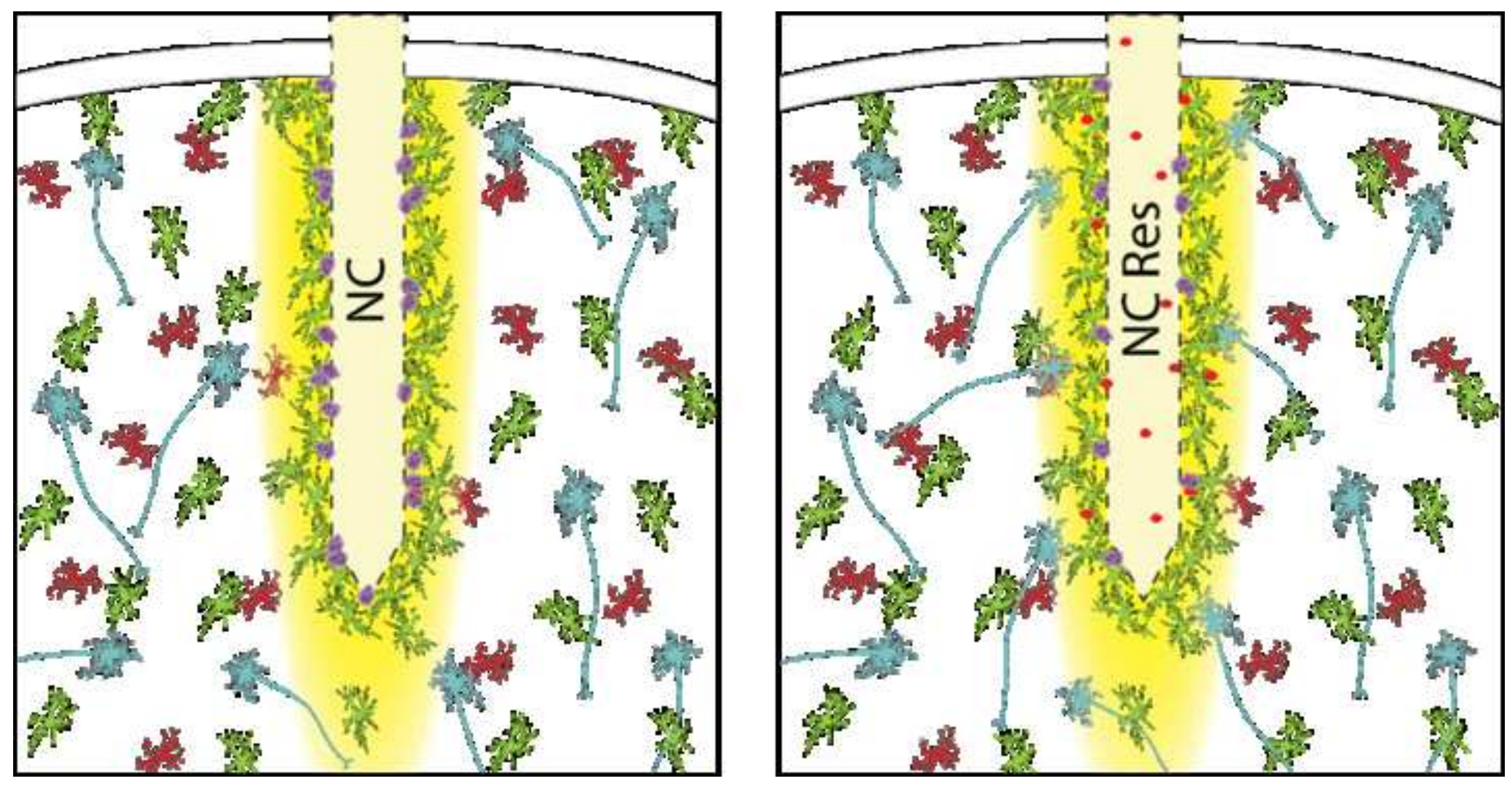